\title{
Ganoderma Lucidum Polysaccharides Enhance CD14 Endocytosis of LPS and Promote TLR4 Signal Transduction of Cytokine Expression
}

\author{
KUO-FENG HUA, ' HSIEN-YEH HSU, ${ }^{1,2 *}$ LOUIS KUOPING CHAO, ${ }^{3}$ SHUI-TEIN CHEN, ${ }^{4}$ \\ WEN-BIN YANG, ${ }^{5}$ JASON HSU, ${ }^{6}$ AND CHI-HUEY WONG ${ }^{5,7}$ \\ 'Department of Biotechnology and Laboratory Science in Medicine, National Yang-Ming University, Taipei, Taiwan \\ ${ }^{2}$ Department of Education and Research, Taipei City Hospital, Taipei, Taiwan \\ ${ }^{3}$ Department of Cosmeceutics, China Medical University, Taichung 404, Taiwan \\ ${ }^{4}$ Institute of Biological Chemistry, Academia Sinica, Taipei, Taiwan \\ ${ }^{5}$ The Genomics Research Center, Academia Sinica, Taipei, Taiwan \\ ${ }^{6}$ Stephen M. Ross School of Business, University of Michigan, Ann Arbor, Michigan \\ ${ }^{7}$ The Scripps Research Institute, La Jolla, California
}

We have previously reported that a well-characterized glycoprotein fraction containing fucose residues in an extract of Ganoderma lucidum polysaccharides (EORP) exerts certain immuno-modulation activity by stimulating the expression of inflammatory cytokines via TLR4. Continuing our studies, we have demonstrated that EORP increases the surface expression of CDI4 and TLR4 within murine macrophages J774A. I cells in vitro, and further promotes LPS binding and uptake by J774A. I cells in a CD I4-dependent fashion. Moreover, we observed the co-localization of internalized LPS with lysosome- and Golgi-apparatus markers within 5 min after J774A.I cells stimulated with LPS. In addition, EORP pretreatment of J774A.I cells and human blood-derived primary macrophages, followed by LPS stimulation, results in the super-induction of interleukin-I beta (IL-I) expression. Endocytosis inhibitors: such as cytochalasin D and colchicine effectively block EORP-enhanced LPS internalization by J774A. I cells; yet they fail to decrease the LPS-induced phosphorylation of certain mitogen-activated protein kinases, and IL-I mRNA and prolL-I protein expression, indicating that LPS internalization by J774A. I cells is not associated with LPS-dependent activation. Our current results could provide a potential EORP-associated protection mechanism for bacteria infection by enhancing IL-I expression and the clearance of contaminated LPS by macrophages.

J. Cell. Physiol. 212: 537-550, 2007. (C) 2007 Wiley-Liss, Inc.

We have previously demonstrated that a glucan-containing extract of Ganoderma lucidum-derived polysaccharides (EORP), a charactered polysaccharides containing essential terminal fucose residues featuring a number of I, 2-linkages, exerts immuno-modulation activity by stimulating the expression of mediators of the normal inflammatory response that occurs within mouse spleen cells (Wang et al., 2002; Chen et al., 2004), human blood-derived macrophages and mouse macrophage cell lines via toll-like receptor 4 (TLR4) (Hsu et al., 2004). We also demonstrated that EORP enhances CD56+ NK-cell cytotoxicity within human cord blood (Chien et al., 2004) and induces immunoglobulin production through the TLR4/ TLR2-mediated induction of transcription factor Blimp-I within $B$ cells (Lin et al., 2006). TLRs are pattern-recognition receptors playing a key role in human and murine innate immunity they detecting microbial infection and following up by triggering antimicrobial host defense responses (Gordon, 2002; Iwasaki and Medzhitov, 2004). Gram-negative bacterial lipopolysaccharide (LPS) is one of potent stimulators of the normal immune response within certain monocytes and macrophages (Raetz and Whitfield, 2002). LPS-binding protein catalyses the transfer of LPS to plasma membranes or to soluble CDI4, which in turn mediate the recognition of LPS through TLR4 (Goyert et al., 1988), leading to the transduction of the multiple signaling of the normal anti-bacterial response, including the production of cytokines (Poltorak et al., 1998).

Contract grant sponsor: National Science Council, Taiwan; Contract grant number: NSC 94-2120-M-010-002 and NSC 93-23I4-B-010-003.

Contract grant sponsor: National Health Research Institutes, Taiwan;

Contract grant number: NHRI-EX93-92IISI.

Contract grant sponsor: Ministry of Education, Taiwan, on Program for Promoting Academic Excellence of Universities;

Contract grant number: A-9I-B-FA09-2-4.

Contract grant sponsor: A grant from Ministry of Education, Aim for the Top University Plan;

Contract grant number: 95A-C-D0I-PPG-10.

Contract grant sponsor: Thematic project, Academia Sinica, Taiwan.

*Correspondence to: Hsien-Yeh Hsu, Department of Biotechnology and Laboratory Science in Medicine, National Yang-Ming University, 155 Li-Nong Street, Shih-Pai Taipei, Taiwan. E-mail: hyhsu@ym.edu.tw Received 10 October 2006; Accepted 10 January 2007

DOI: $10.1002 /$ jcp.21050 
Phagocytosis is the process, by which macrophages ingest particulate ligands, and it is a process that is critical for innate immunity (Stuart and Ezekowitz, 2005). In the course of sepsis, the processes of physical neutralization and internalization of LPS by immune cells are important for the detoxification of LPS; subsequent to endocytosis, LPS is, typically biologically deactivated by certain specific enzymes (Munford and Hall, 1986). Recently, it has been demonstrated that CDI4, but not TLR4, plays a key role in LPS uptake mechanisms by murine macrophages (Latz et al., 2002; Dunzendorfer et al., 2004), whereas for CDI4-negative cells, scavenger receptors have been implicated in the clearance of exogenous LPS (Hampton et al., I99I). Endocytosis of LPS has been reported to activate endotoxin-dependent signal transduction within murine cardiomyocytes (Cowan et al., 200I), whereas for human monocytic THP-I cells, LPS-mediated signaling is, reportedly, independent of LPS internalization (Poussin et al., 1998). It has been reported previously that polysaccharides purified from G. lucidum are able to enhance human neutrophil phagocytosis and chemotaxis (Hsu et al., 2003); however, the effect of $G$. lucidum polysaccharides upon LPS endocytosis by macrophages would appear to be somewhat unclear.

The IL-I cytokine, involved in several inflammatory and immunologic processes, is, reportedly, produced by activated human and murine monocytes/macrophages, as well as by many other cell types (Dinarello, 1996). A precursor form of IL-I, referred to as prolL-I, is, reportedly, translated from IL-I mRNA and cleaved into a I7-kDa mature secreted form of IL- I by interleukin- I converting enzyme (ICE) (Cerretti et al., I 992). IL-I represents a potent inflammatory cytokine featuring numerous biological activities that regulate host defense and immune responses (Loppnow et al., 1998). Mice pretreated with recombinant IL-I prior to infection with Escherichia coli reveal significantly reduced mortality rates compared with mice that do not undergo such pretreatment (Joshi et al., 2002). The potentially beneficial functions of IL-I, however, do require some modulation, on occasion, in order to avoid causing serious damage including shock and organ failure associated with sepsis (Waage and Espevik, 1988), and joint inflammation for cases of rheumatoid arthritis (Kay and Calabrese, 2004) following the administration or overexpression of IL-I to the individual. One of the endogenous forms of modulation of IL-I activity is achieved via the production of interleukin-I receptor antagonist (IL-IRa), a member of the IL-I family and one which binds to IL-I receptors, but does not induce any intracellular response compared to IL-I stimulation (Hannum et al., 1990). Studies involving transgenic and knockout mice indicate that IL-IRa is important for the normal host defense against LPS-induced injury in mice (Hirsch et al., 1996).

In order to examine the impact of EORP upon LPS endocytosis and LPS-dependent cytokine expression, we have used confocal microscopy and flow cytometry to demonstrate that EORP enhances CDI4 and TLR4 surface expression and promotes LPS endocytosis within cultured murine macrophages. In addition, we have used mice and a specific macrophage model to present the evidence that IL-IRa expression was increased upon EORP injection and stimulation, respectively, as well as enhancing LPS-induced activation of ERK, JNK, and p38, leading to the up-regulation of downstream IL-I gene expression.

\section{Materials and Methods}

\section{Cell cultures}

Using Histopaque ${ }^{\mathbb{R}}$ - 1077 method, human blood monocytes-derived macrophages were isolated from blood of healthy persons obtained from Taiwan Blood Center (Taipei, Taiwan). J774A.I cells were obtained from ATCC (Rockville, MD). All cell cultures were propagated in RPMI 1640 medium supplemented with 10\% heated-inactivated fetal bovine serum and $2 \mathrm{mML}$-glutamine and cultured in a $37^{\circ} \mathrm{C}, 5 \% \mathrm{CO}_{2}$ incubator.

\section{Study of IL-I production challenged with LPS and EORP} in mice model

Male C57BL/6] mice (8-10 weeks old and averaged 18-22 g) were purchased from National Laboratory Animal Center (Taipei, Taiwan). All animal procedures were conducted under a license from the Institutional Animal Care and Use Committee at the National Yang-Ming University. Mice were intra-peritoneal injected of $100 \mathrm{mg} /$ $\mathrm{kg}$ EORP, $5 \mathrm{mg} / \mathrm{kg}$ LPS or an equal volume $(200 \mu \mathrm{l})$ of PBS $24 \mathrm{~h}$ before $10 \mathrm{mg} / \mathrm{kg}$ LPS or $200 \mathrm{mg} / \mathrm{kg}$ EORP challenges. Sera were collected after LPS or EORP challenge for assessment of IL-I and TNF expression.

\section{Materials}

LPS, FITC-LPS (from E. coli 0 I I I:B4), Histopaque ${ }^{\circledR}$ - 1077, anti-MAP kinase, activated (diphosphorylated ERK) antibody, anti-JNK kinase, activated (diphosphorylated JNK) antibody, anti-p38 MAP kinase, activated (diphosphorylated p38) antibody, and anti-actin antibody were purchased from Sigma Co. (St. Louis, MO). Anti-rabbit IgG-HRP, anti-mouse lgG-HRP, and anti-IL-I antibody were obtained from Santa Cruz Biotechnology (Santa Cruz, CA); anti-mouse TLR4 blocking antibody and PE-conjugated anti-mouse TLR4 antibody were obtained from IMGENEX Corporation (Carlsbad, CA); PE-conjugated antimouse CDI4 antibody was obtained from BD Biosciences (Mountain View, CA); anti-mouse macrophage scavenger receptor (MSR) antibody (2F8) and FITC-conjugated MSR antibody were obtained from Serotec, Inc. (Oxford, UK). Mouse IL-I Enzyme-Linked

Immunosorbent Assay (ELISA) Kit was purchased from R\&D Systems, Inc. (Minneapolis, MN). Human IL-I and TNF ELISA Kit were purchased from BioSource International, Inc. (Camarillo, CA). Primers for RT-PCR of IL-I and glyceraldehydes phosphate dehydrogenase (GAPDH) were synthesized from MDBio. Inc. (Taipei, Taiwan). The LysoTracker $^{\text {TM }}$ Red DND-99 and BODIPY TR $\mathrm{C}_{5}$-ceramide were purchased from Molecular Probes, Inc. (Eugene, OR).

\section{Preparation of EORP, RNA isolation, RT and PCR amplification for detecting the expression of IL-I, Western Blotting Analysis, ELISA for measurement of IL-I and ICE activity assay}

All detail methods and procedures were followed the previous methods (Hsu et al., 2004).

\section{Flow cytometric analysis}

For cell surface expression experiments of TLR4, CDI4, and MSR, J774A. I cells were incubated with medium (control), EORP $(25 \mu \mathrm{g} / \mathrm{ml})$, LPS (I $\mu \mathrm{g} / \mathrm{ml})$, fucoidan $(25 \mu \mathrm{g} / \mathrm{ml})$, FI fraction of Reishi $(25 \mu \mathrm{g} / \mathrm{ml})$, or F2 fraction of Reishi $(25 \mu \mathrm{g} / \mathrm{ml})$ for $24 \mathrm{~h}$. Cells were fixed and cell surface expression of TLR4, CDI 4 or MSR were measured by staining cells for 30 min with PE-conjugated anti-TLR4 antibody, PE-conjugated anti-CDI 4 antibody, or FITC-conjugated MSR antibody on ice, respectively. After washing, cells were subjected to flow cytometric analysis on FACSCalibur using CellQuest Software of Becton Dickinson Inc. (San Jose, CA). Experiments for binding of LPS to cell surface, J774A.I cells were incubated with medium, EORP $(25 \mu \mathrm{g} / \mathrm{ml})$ or LPS (I $\mu \mathrm{g} / \mathrm{ml})$ for $24 \mathrm{~h}$. After fixation, cells were incubated with FITC-LPS for 30 min at $4^{\circ} \mathrm{C}$. After washing, cells were subjected to flow cytometric analysis. For LPS uptake experiments, J774A. I cells were incubated with medium, EORP $(25 \mu \mathrm{g} / \mathrm{ml})$ or LPS $(\mathrm{l} \mu \mathrm{g} / \mathrm{ml})$ for $24 \mathrm{~h}$. After washing, cells were incubated with FITC-LPS for I $\mathrm{h}$ at $37^{\circ} \mathrm{C}$. After incubation, cells were washed twice with PBS and further treated with proteinase $\mathrm{K}(250 \mu \mathrm{g} / \mathrm{ml})$ for $30 \mathrm{~min}$ at room temperature to remove cell surface proteins/receptors and surface-bound LPS (Kitchens and Munford, 1998). The remaining LPS were considered to be intracellular and FITC-LPS in J774A.I cells were measured by flow cytometric analysis.

\section{Confocal microscope analysis}

For LPS cell surface binding experiments, J774A.I cells were incubated with medium or EORP $(25 \mu \mathrm{g} / \mathrm{ml})$ for $24 \mathrm{~h}$. Cells were fixed and incubated with TLR4 blocking antibody $(10 \mu \mathrm{g} / \mathrm{ml})$, CDI4-blocking antibody $(10 \mu \mathrm{g} / \mathrm{ml})$, or control antibody $(10 \mu \mathrm{g} / \mathrm{ml})$ for $30 \mathrm{~min}$, followed by incubation of FITC-LPS for $30 \mathrm{~min}$ at $4^{\circ} \mathrm{C}$. For LPS uptake 
experiments, cells were incubated with medium or EORP $(25 \mu \mathrm{g} / \mathrm{ml})$ for $24 \mathrm{~h}$. After washing, cells were incubated with TLR4 blocking antibody $(10 \mu \mathrm{g} / \mathrm{ml})$, CDI4-blocking antibody $(10 \mu \mathrm{g} / \mathrm{ml})$, control antibody $(10 \mu \mathrm{g} / \mathrm{ml})$, cytochalasin D $(10 \mu \mathrm{M})$ or colchicines $(30 \mu \mathrm{M})$ for 30 min, followed by incubation of FITC-LPS for I h at $37^{\circ} \mathrm{C}$. For TLR4 and CD 4 expression, cells were incubated with EORP $(25 \mu \mathrm{g} / \mathrm{ml})$ for $24 \mathrm{~h}$, followed by staining with PE-conjugated anti-TLR4 antibody or PE-conjugated anti-CDI 4 antibody for $2 \mathrm{~h}$ at room temperature. For TLR4/Golgi and CDI4/Golgi co-localization experiments, cells were incubated with medium or EORP $(25 \mu \mathrm{g} / \mathrm{ml})$ for $24 \mathrm{~h}$. After washing, cells were incubated with BODIPY TR $\mathrm{C}_{5}$-ceramide $(\mathrm{I} \mu \mathrm{M})$ at $4{ }^{\circ} \mathrm{C}$ for $30 \mathrm{~min}$, followed by stained with FITC-conjugated TLR 4 or CDI4 antibody at $4{ }^{\circ} \mathrm{C}$ for additional $2 \mathrm{~h}$. For LPS/lysosomes and LPS/Golgi co-localization experiments, cells were incubated with EORP $(25 \mu \mathrm{g} /$ $\mathrm{ml})$

for $24 \mathrm{~h}$. After washing, cells were incubated with LysoTracker ${ }^{\mathrm{TM}}$ Red DND-99 (I $0 \mathrm{nM})$ or BODIPY TR $\mathrm{C}_{5}$-ceramide $(\mathrm{I} \mu \mathrm{M})$ at 37 and $4{ }^{\circ} \mathrm{C}$ for $30 \mathrm{~min}$, respectively, followed by FITC-LPS $(\mathrm{I} \mu \mathrm{g} / \mathrm{ml})$ stimulation for 0-30 min. After washing, cells were visualized using a Leica TLS SP2 confocal microscope (Leica Lasertechnik, Heidelberg, Germany).

\section{Statistical analysis}

Statistical differences between the experimental groups were examined by analysis of variance, and statistical significance was determined at $P<0.05$. The experiments were conducted three times or as indicated, all data are expressed as mean $\pm \mathrm{SE}$.
Results

EORP increases macrophage-membrane surface expression of TLR4 and CDI4

The activation and modulation of TLR4 is an important early step in either EORP- (Hsu et al., 2004) or LPS-mediated signal transduction in the regulation of IL-I gene expression (Hsu and Wen, 2002), thus we were interested in examining the effect of EORP (i.e., fraction 3, F3) upon TLR4 surface expression.

Initially, using flow cytometry analysis, we demonstrated that EORP specifically up-regulates cultured murine macrophages J774A. I cells surface expression of TLR4 as indicated by mean fluorescence intensity (MFI) (Fig. IA, left part), although this is not the case for any of the other Reishi polysaccharide F3-relevant fractions (e.g., fractions I and 2, FI and F2) (Wang et al., 2002), nor is it the case for fucoidan, a principal fucose polysaccharide sulfate ester found in brown seaweeds,

Phaeophyceae species (Hsu et al., 200I). By contrast, we found that LPS treatment down-regulates J774A.I cells surface expression of TLR4 (Fig. IA, left part), an observation, which is similar to that, reported in another LPS tolerance study featuring cultured murine macrophage cells RAW264.7 (Nomura et al., 2000). In the following investigation, while examining the cell membrane expression of CDI4, which involved, importantly, LPS-mediated signaling, we found that
A
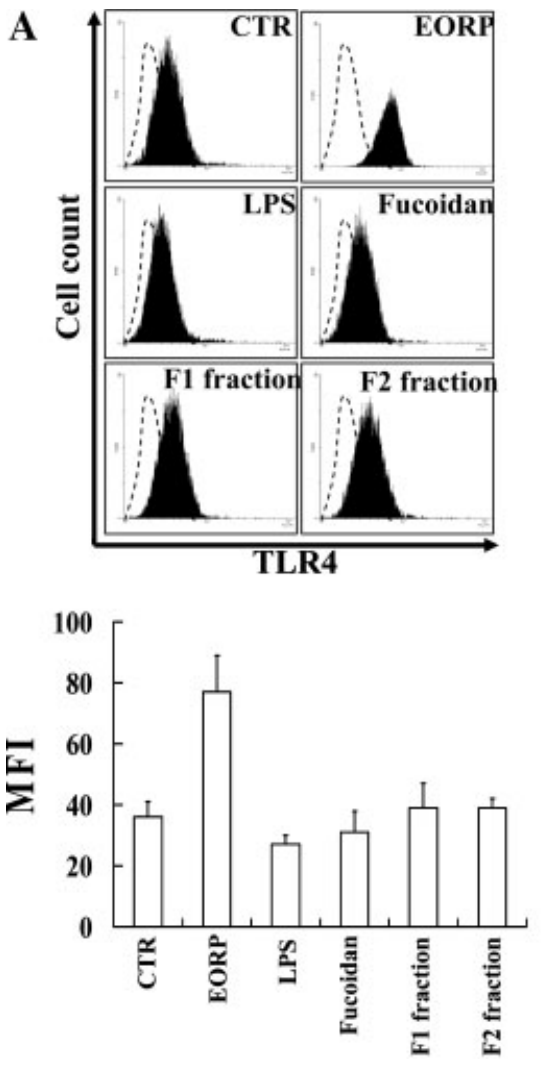
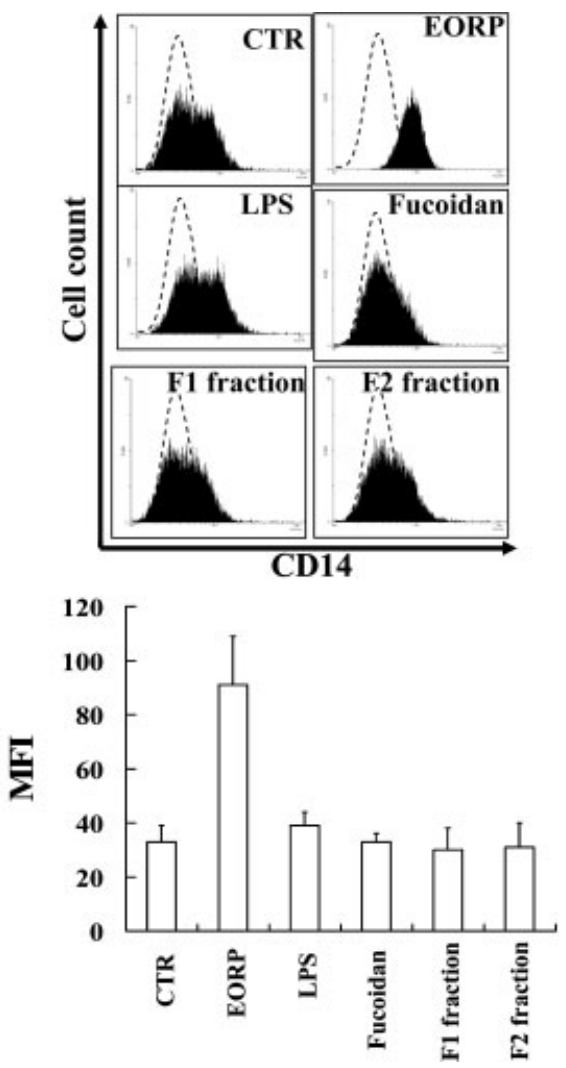

Fig. I. EORP increases surface expression of TLR4 and CD 14 within J774A.I cells. A: J774A.I cells were incubated with one of EORP (25 $\mu \mathrm{g} / \mathrm{ml})$, LPS (I $\mu \mathrm{g} / \mathrm{ml})$, fucoidan $(25 \mu \mathrm{g} / \mathrm{ml})$, FI fraction of Reishi $(25 \mu \mathrm{g} / \mathrm{ml})$ or F2 fraction of Reishi $(25 \mu \mathrm{g} / \mathrm{ml})$ for $24 \mathrm{~h}$, fixed with $2 \%$ paraformaldehyde, followed by stained with PE-conjugated TLR4 or CDI 4 antibody for 30 min, then analyzed by flow cytometry. Dotted line: isotype control antibody; shade histograms: treatment as indicated. The histograms were quantified and represent as mean fluorescence intensity (MFI). B: J774A.I cells were incubated with medium or EORP $(25 \mu \mathrm{g} / \mathrm{ml})$ for $24 \mathrm{~h}$, followed by stained with PE-conjugated TLR4 or CDI 4 antibody, then analyzed by confocal microscope. C: J774A.I cells were labeled with BODIPY TR $\mathrm{C}_{5}$-ceramide $(\mathrm{I} \mu \mathrm{M})$ at $4^{\circ} \mathrm{C}$ for 30 min followed by fixed with $2 \%$ paraformaldehyde and permeated with $0.1 \%$ Triton X-100, cells were stained with FITC-conjugated TLR 4 or CD I 4 antibody, and then analyzed by confocal microscope. Merged images of Golgi marker and TLR4 or CD I 4 are indicated by arrows. [Color figure can be viewed in the online issue, which is available at www.interscience.wiley.com.] 
B

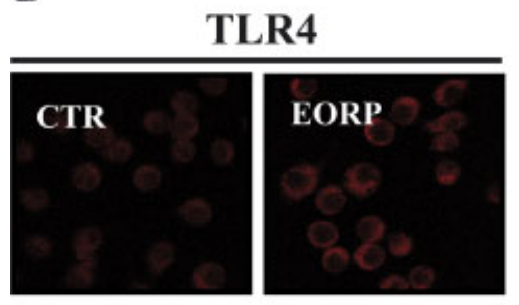

CD14

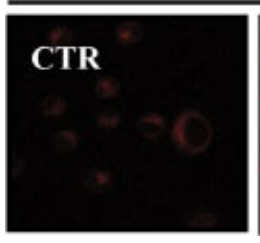

C

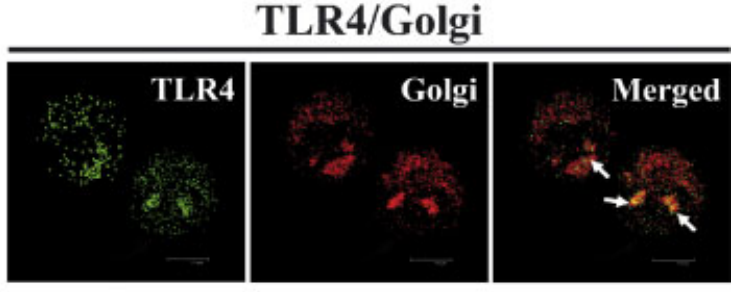

CD14/Golgi

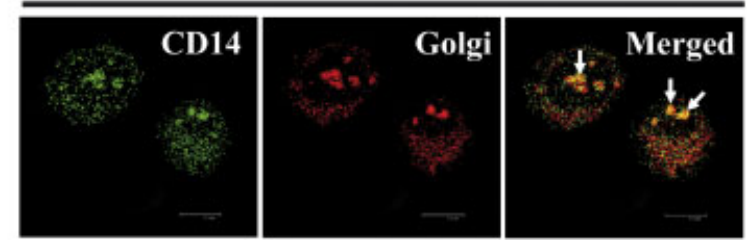

Fig. I. (Continued)

EORP significantly increases CDI4 surface expression (Fig. IA, right part); but that there was no such analogous effect of LPS, FI, F2, and fucoidan upon CDI4 expression. Moreover, using confocal microscopy, we further confirmed that only EORP, and no other above-mentioned polysaccharides, is able to increase the surface expression of TLR4 and of CDI4 by J774A.I cells (Fig. IB). It has been reported that TLR4 is localized to the Golgi apparatus within murine small intestinal epithelial cells (Hornef et al., 2002). To identify the cytoplasmic compartment harboring TLR4 within macrophages, double immuno-fluorescent staining was performed using BODIPY TR $C_{5}$-ceramide, a fluorescent structural marker for Golgi complex, and FITC-conjugated TLR4 antibody. Markers of the Golgi complex BODIPY TR $\mathrm{C}_{5}$-ceramide showed a partially co-localization with TLR4 staining (Fig. IC), suggesting a widespread distribution of TLR4 in the Golgi complex. Also, we found CDI4 is partial harboring in the Golgi complex within J774A.I cells (Fig. IC). In addition, MSR is considered to be a binding receptor of LPS (Hampton et al., I991), yet interestingly, we found that EORP decreases J774A.I cell surface expression of MSR, however, LPS was also observed to up-regulate J774A. I cell surface expression of MSR (data not shown).

\section{EORP enhances LPS recognition/binding affinity and LPS uptake/clearance within macrophages}

It has been previously reported that Reishi polysaccharides enhance neutrophil phagocytosis (Hsu et al., 2003). Here we examined whether EORP pretreatment of J774A.I cells affects LPS recognition/binding and uptake/clearance by J774A.I cells. Initially, using confocal microscopy to observe the results of an LPS binding assay, we found that subsequent to the incubation of FITC-conjugated LPS (FITC-LPS) with fixed J774A.I cells at $4{ }^{\circ} \mathrm{C}$ for a period of $30 \mathrm{~min}$, the amount of cell surface-bound LPS was substantially greater for EORP-pretreated J774A.I cells (Fig. 2A, part C-2), than was the case for medium-pretreated J774A.I cells, that is, control cells (Fig. 2A, part C-I). Following this work, we analyzed the role of TLR 4 and that of CDI 4 in LPS recognition/binding by J774A.I cells. As can be seen, pretreatment of J774A.I cells with CD 4 blocking antibody (Fig. 2A, part C-4), but not with TLR4 blocking antibody (Fig. 2A, part C-3) prior to FITC-LPS stimulation resulted in significantly reduction of LPS binding to J774A. I cells surface, indicating that CDI 4 plays a more important role than TLR4 in LPS binding to J774A. I cells. In addition, using flow cytometry analysis, we further confirmed that pretreatment of J774A.I cells with EORP, but not LPS, enhances FITC-LPS binding to the cell surface of J774A.I cells (Fig. 2B).

Alternatively, in order to examine the effect of EORP upon LPS uptake/clearance, we first pretreated J774A.I cells with EORP or medium (control), followed by incubation of J774A.I cells with FITC-LPS at $37^{\circ} \mathrm{C}$ for a period of I $\mathrm{h}$. Under confocal microscopy-assisted analysis of the endocytosis of FITC-LPS, we found that EORP significantly increases J774A.I cells FITC-LPS uptake/clearance (Fig. 2C, part C-2), compared to analogous cells treated with medium alone (Fig. $2 \mathrm{C}$, part $\mathrm{C}-\mathrm{I}$ ). In subsequent investigation, we further demonstrated that the

Fig. 2. EORP increases LPS binding and internalization by J774A. I cells. A: J774A. I cells were treated with medium or EORP (25 $\mu$ g/ml) for $24 \mathrm{~h}$ followed by fixed with $2 \%$ paraformaldehyde. Cells were incubated with control antibody ( $10 \mu \mathrm{g} / \mathrm{ml})$, TLR4 blocking antibody (I $0 \mu \mathrm{g} / \mathrm{ml})$, or CD I 4 blocking antibody $(10 \mu \mathrm{g} / \mathrm{ml})$ for $30 \mathrm{~min}$, followed by incubated with FITC-LPS $(1 \mu \mathrm{g} / \mathrm{ml})$ (green) at $4^{\circ} \mathrm{C}$ for $30 \mathrm{~min}$, and then examined by confocal microscope. Part A: phase contrast images; part B: fluorescent images; part C: merged images. B: EORP, but not LPS pretreatment increase LPS binding to J774A. I cells. J774A. I cells were incubated with medium, EORP ( $25 \mu \mathrm{g} / \mathrm{ml})$ or $\mathrm{LPS}$ (I $\mu \mathrm{g} / \mathrm{ml}) \mathrm{for} 24 \mathrm{~h}$ followed by fixed with $2 \%$ paraformaldehyde. Cells were incubated with FITC-LPS $(1 \mu \mathrm{g} / \mathrm{ml})$ at $4^{\circ} \mathrm{C}$ for 30 min, and then examined by flow cytometry. Dotted line: no FITC-LPS control; shade: treatment as indicated. The histograms were quantified and represent as mean fluorescence intensity (MFI). C: EORP pretreatment increases LPS internalization by J774A. I cells. J774A. I cells were incubated with medium or EORP (25 $\mu$ g/ml) for 24 h. After washing, cells were incubated with control antibody ( $10 \mu \mathrm{g} / \mathrm{ml})$, TLR4 blocking antibody (I $0 \mu \mathrm{g} / \mathrm{ml})$ or CD I 4 blocking antibody (I $0 \mu \mathrm{g} / \mathrm{ml})$ for $30 \mathrm{~min}$, followed by incubated with FITC-LPS $\left(\mathrm{I} \mu \mathrm{g} / \mathrm{ml}\right.$ ) (green) at $37^{\circ} \mathrm{C}$ for I h. After fixation and proteinase $\mathrm{K}(250 \mu \mathrm{g} / \mathrm{ml})$ treatment, cells were examined by confocal microscope. Part A: phase contrast images; part B: fluorescent images; part C: merged images. D: EORP pretreatment specifically increases LPS internalization by J774A.I cells. J774A.I cells were incubated with one of EORP (25 $\mu$ g/ml), LPS (I $\mu$ g/ml), fucoidan $(25 \mu \mathrm{g} / \mathrm{ml})$, FI fraction of Reishi $(25 \mu \mathrm{g} / \mathrm{ml})$, and F2 fraction of Reishi $(25 \mu \mathrm{g} / \mathrm{ml})$ for $24 \mathrm{~h}$, followed by incubation with FITC-LPS (I $\mu \mathrm{g} / \mathrm{ml})$ at $37^{\circ} \mathrm{C}$ for I h. After proteinase $\mathrm{K}(250 \mu \mathrm{g} / \mathrm{ml})$ treatment, cells were analyzed by flow cytometry. Dotted line: no FITC-LPS control; shade histograms: treatment as indicated. The histograms were quantified and represent as mean fluorescence intensity (MFI). [Color figure can be viewed in the online issue, which is available at www.interscience.wiley.com.] 
CDI4 blocking antibody (Fig. 2C, part C-4), but not the TLR4 blocking antibody (Fig. 2C, part C-3) blocks LPS uptake/ clearance by J774A.I cells significantly, indicating that CDI4 plays a more-important role than TLR4 in the endocytosis of LPS within J774A.I cells. Furthermore, using flow-cytometry analysis, we also confirmed that pretreatment of J774A.I cells with EORP enhances FITC-LPS uptake/clearance by J774A.I cells; and, in addition, LPS pretreatment enhances FITC-LPS uptake/clearance by J774A. I cells, although by only a slight amount. Pretreatment of other EORP-related polysaccharide fractions, for example, $\mathrm{FI}$ and F2, and fucoidan, however, did not increase LPS uptake/clearance, indicating that EORP (i. e., F3) specifically facilitates macrophages uptake/clearance of LPS (Fig. 2D).
A
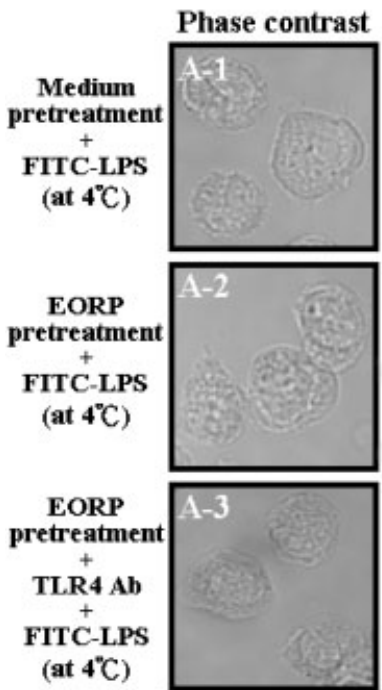

EORP pretreatment CD14 Ab FITC-I.PS (at $4^{\circ} \mathrm{C}$ )

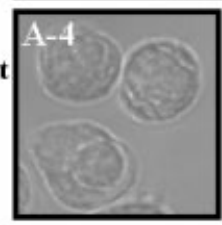

C
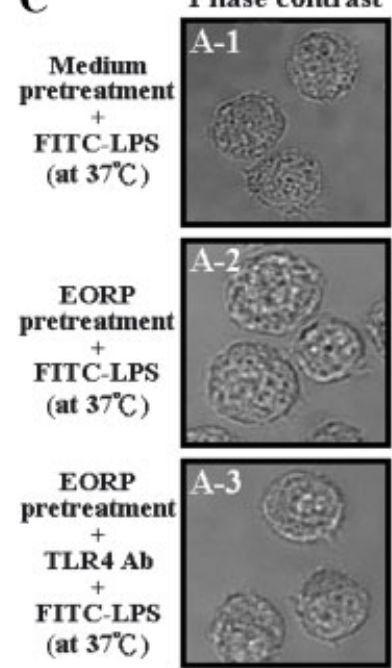

(a) EORP
pretreatment $+$

CD14 Ab

FITC-LPS (at $37^{\circ} \mathrm{C}$ )
B
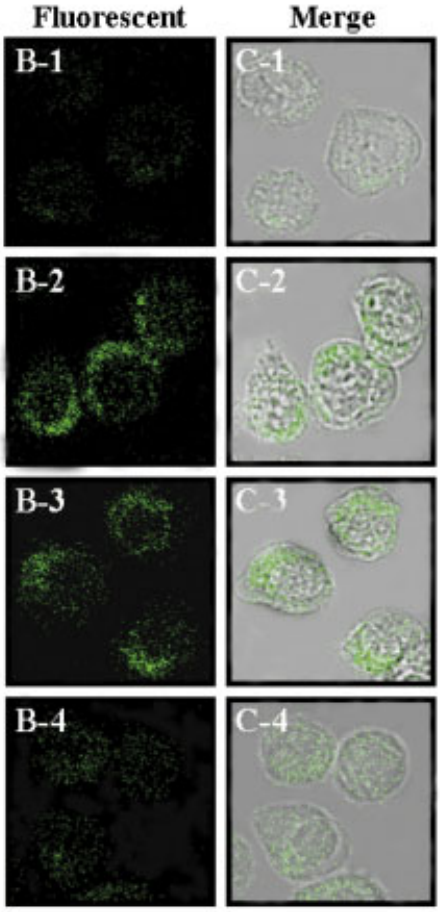

Fluorescent
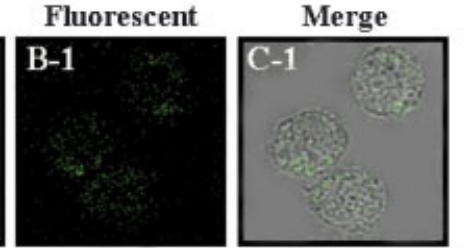

D
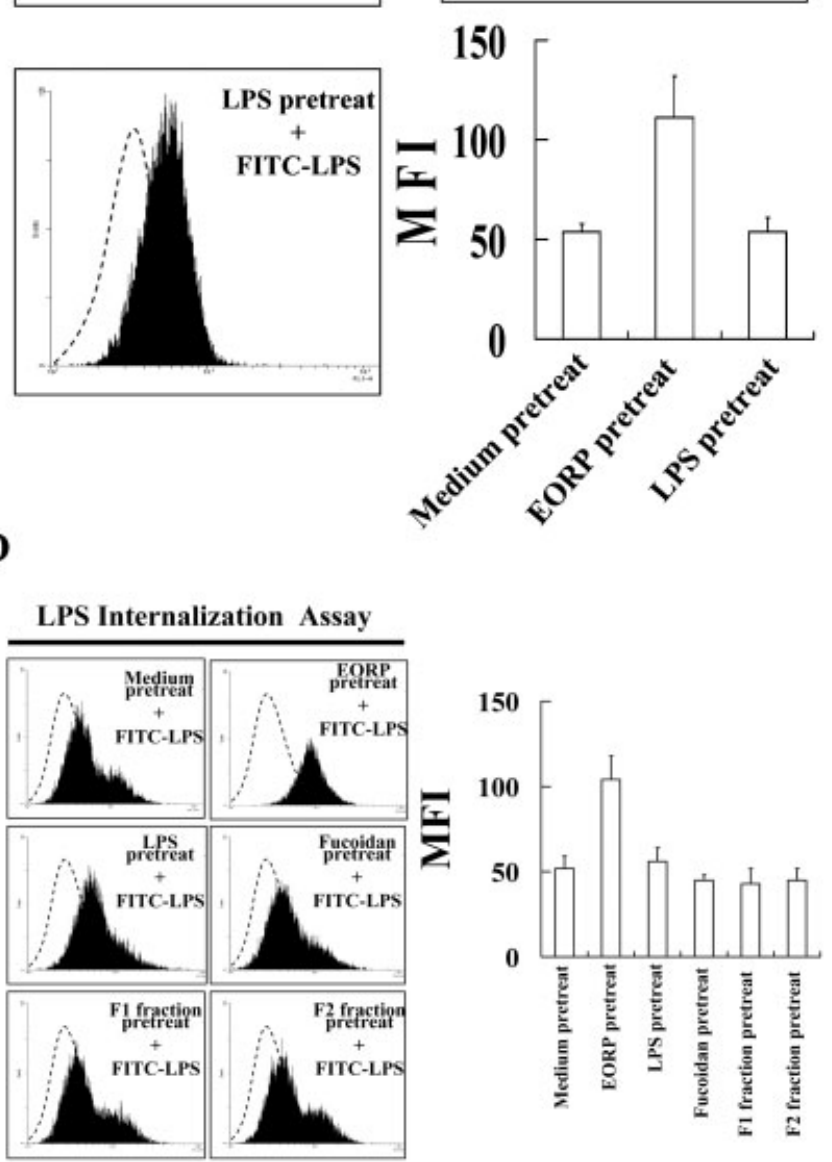

Fig. 2. 
Co-localization of internalized LPS with lysosome and Golgi apparatus markers

It has been demonstrated previously that internalized LPS move transiently into an acidic intracellular compartment of human neutrophils (Munford and Hall, 1986). In our current study, in order to examine whether LPS also moves into lysosomes after uptake by J774A. I cells, we used a fluorescent, freely cell membrane permeable probe, LysoTracker ${ }^{\text {TM }}$ Red DND-99 (LysoTracker), which features a high selectivity for acidic organelles (Via et al., 1998). LysoTracker-prelabelled J774A.I cells were incubated with FITC-LPS at $37^{\circ} \mathrm{C}$ for various periods of time, including: $0,5,15$, and $30 \mathrm{~min}$; followed by observation under confocal microscopy while cells were still viable.

Endocytosis-mediated internalized LPS can be detected as early as 5 min and subsequent to a 30 - min period of LPS internalization subsequent to initial stimulation

(Fig. 3A, samples AI-A4). LPS was detected in a perinuclear area of J774A. I cells and distributed in a tubular pattern after uptake by J774A.I cells, an observation which is similar to that reported in LPS uptake by murine peritoneal macrophages (Thieblemont and Wright, 1997); yet by contrast, the fluorescent lysosomes were distributed throughout the cytoplasm of J774A.I cells (Fig. 3A samples BI-B4). The results of merging FITC-LPS and LysoTracker processes revealed that the test cell cellular compartment containing the internalized FITC-LPS partially overlapped the lysosomes (Fig. 3A, samples $\mathrm{CI}-\mathrm{C} 4)$. On the other hand, the Golgi apparatus of test J774A.I cells could be selectively stained with a fluorescent dye BODIPY TR $\mathrm{C}_{5}$-ceramide (BODIPY), which tends to associate preferentially with the trans-Golgi complex (Lipsky and Pagano, 1985). The results of cellular staining assay showed that the punctuate pattern of labelled cells appeared to be similar when stained with either LPS or BODIPY, and that the brightly labelled LPS-containing vesicles colocalized with BODIPY fluorescence during the above-mentioned FITC-LPS uptake assay period of from 0 to $30 \mathrm{~min}$ at $37^{\circ} \mathrm{C}$ (Fig. 3B, samples $\mathrm{Cl}-\mathrm{C} 4)$. Comparing the fluorescence intensity in the Golgi

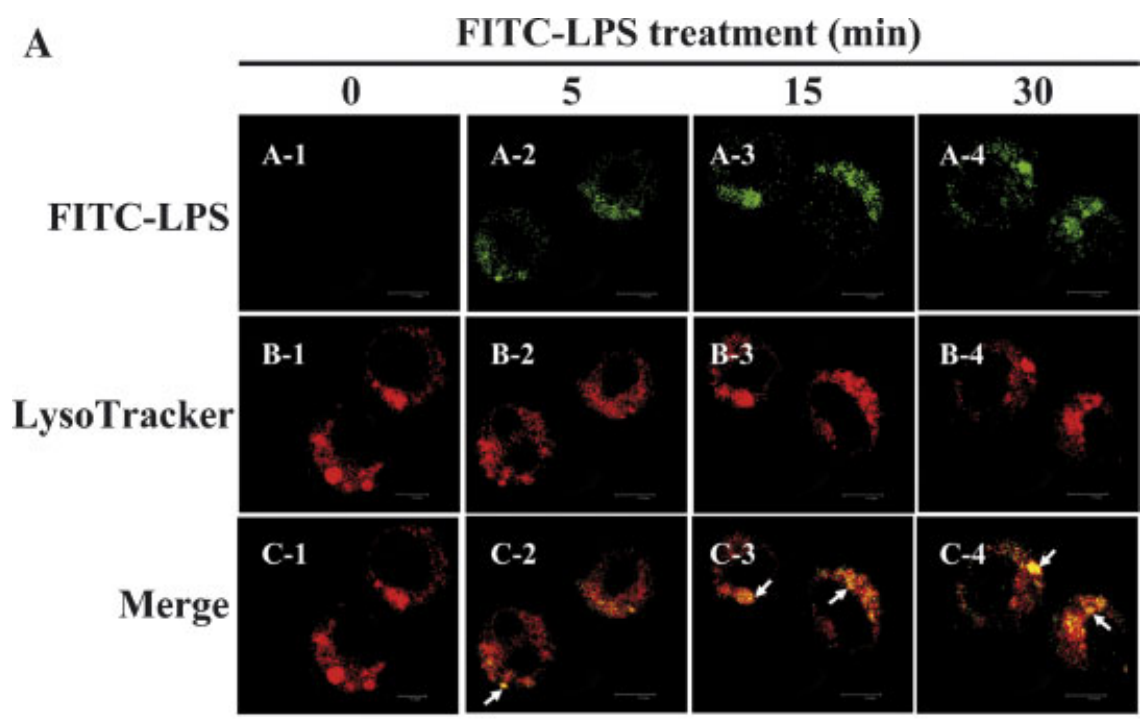

B

FITC-LPS treatment (min)

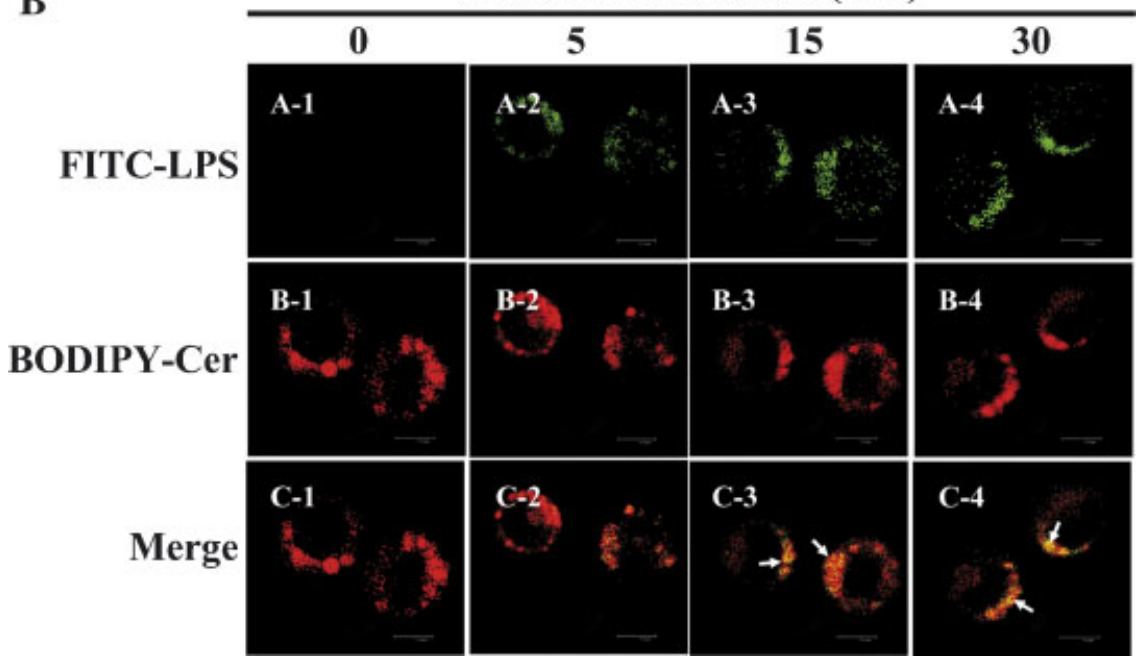

Fig. 3. Co-localization of internalized LPS with lysosome and Golgi apparatus markers. Intracellular distribution of LPS and organelle markers within J774A.I cells. Markers of (A) lysosome (LysoTracker) or (B) Golgi (BODIPY-Cer) were incubated with FITC-LPS at 37 ${ }^{\circ} \mathrm{C}$ for 0-30 min and processed for microscopy. Part A: fluorescence for LPS alone; Part B: the organelle marker alone; Part C: merged image of LPS and organelle marker as indicated by arrows. [Color figure can be viewed in the online issue, which is available at www.interscience.wiley.com.] 
apparatus of J774A.I cells to the fluorescent intensity detected in corresponding lysosomes, there would appear to be a stronger co-localization of FITC-LPS and Golgi apparatus, suggesting that more FITC-LPS molecules accumulate in the Golgi apparatus of J774A. I cells after FITC-LPS being internalized than congregate within lysosomes. Based upon the current observations showed in Figure 3, vesicular transport from the plasma membrane of J774A.I cells appears to deliver FITC-LPS to the Golgi apparatus and also to the lysosome, however, other delivery sites for fluorescent-labeled LPS probably also include endosomes and the endoplasmic reticulum of J774A. I cells after LPS internalization (Kriegsmann et al., 1993), both of which delivery-site options warranting further investigation.

\section{EORP increases IL-I secretion within LPS-stimulated human primary macrophage and within murine macrophage J774A.I cells}

From our investigations, we observed that pretreatment of J774A. I cells with EORP or a mixture of EORP and LPS (EORP/ LPS) followed by incubation with LPS for a period of $24 \mathrm{~h}$, significantly increased IL- I secretion by J774A. I cells compared to the case for EORP-free controls (Fig. 4A, samples 3 and 4 vs. I and 2). From the results of an EORP dose-response study of J774A.I cells, if the concentration of EORP pretreatment of J774A.I cells was greater than $25 \mu \mathrm{g} / \mathrm{ml}$ for $24 \mathrm{~h}$, such pretreatment resulted in the LPS-mediated hyperesponsiveness of IL-I secretion from J774A.I cells (Fig. 4B). Following such experimentation, we found that pretreatment of either human primary macrophages or J774A. I cells (Fig. 4C) with EORP for a period of $24 \mathrm{~h}$ substantially increased LPS-induced IL-I secretion compared to the case for EORP-free controls. Moreover, within $24 \mathrm{~h}$ of EORP pretreatment, IL-I secretion into culture supernatant from cultured human macrophages and murine J774A.I cells was observed to be, respectively, $25 \mathrm{ng} / \mathrm{ml}$ and I $\mathrm{ng} / \mathrm{ml}$, indicating different reaction kinetics as regards IL-I secretion apply for human macrophages and J774A.I cells.

\section{Preinjection of EORP increases IL-I secretion for LPS-injected mice in vivo}

As part of our further investigation, we tested the in vivo effect of EORP upon LPS-induced cytokine expression for C57BL/6] mice. In brief, C57BL/6] mice were initially injected intraperitoneally (i.p.) with one of the following, PBS, LPS or EORP. Twenty-four hours subsequent to such injection, mice were again i.p. injected with PBS, LPS, or EORP, I.5 h following which, the concentration of IL- $I$ in the serum of the tested mice was measured by means of ELISA (Fig. 4D). The mice initially i.p. injected with PBS, EORP, or LPS were defined as group $A$, group $B$, and group C, respectively. Group A mice (Fig. 4D, samples $1-3)$, revealed that a second LPS injection increased the baseline level of IL-I secretion by C57BL/6) mice ( $550 \mathrm{pg} / \mathrm{ml}$, sample 3) more substantially than was the case for EORP injection ( 100 pg/ml, sample 2) or for PBS injection (control) mice (basal level, sample I). For group B, mice were initially i.p. injected with EORP for $24 \mathrm{~h}$, followed by a second injection with one of PBS, EORP, or LPS for I.5 h (samples 4-6, respectively). The results of such treatment indicated that EORP significantly increased LPS injection-induced IL-I secretion from mice ( $\sim 800 \mathrm{pg} / \mathrm{ml}$, sample 6$)$, such increase in IL-I secretion not being the case for mice injected with either EORP $(\sim 50 \mathrm{pg} / \mathrm{ml}$, sample 5) or PBS (basal level, sample 4) as the second injection. For group C, mice were initially injected with LPS for a period of $24 \mathrm{~h}$, followed by again injection with one of PBS, EORP or LPS (samples 7-9, respectively). A second injection of LPS induces lower IL-I secretion in mice serum ( $\sim 400 \mathrm{pg} / \mathrm{ml}$, sample 9) compared to the case for single LPS injected mice (group A, sample 3). By contrast, EORP and PBS injection did not induce significantly IL-I secretion in mice serum (samples 6 and 7). Although EORP was observed to increase LPS-induced IL-I expression by J774A.I cells, it did not increase the relative toxicity of LPS C57BL/6] mice (data not shown), thus we tested the hypotheses that EORP was able to stimulate some sort of "protection" factors from cultured J774A.I cells. We investigated whether it was possible for EORP to increase the level of IL-I receptor antagonist (IL-I Ra) expression. As can be seen from Figure 4E, there appears to be no evidence of the presence of IL-IRa in the serum of PBS-injected mice or control mice. By contrast, however, at $3 \mathrm{~h}$ post-EORP injection of test mice, we noted that IL-IRa concentration in mice serum was substantially induced by the injection of EORP, the level of IL-IRa reaching to around $5,000 \mathrm{pg} / \mathrm{ml}$ in mice serum $3 \mathrm{~h}$ subsequent to EORP injection, although we also observed that LPS injection into C57BL/6J mice increased IL-I Ra concentration in serum. In addition, EORP treatment also increases IL-IRa secretion from cultured J774A. I cells and human primary macrophages (data not shown).

\section{Mechanism by which the pretreatment of macrophages with EORP increasing LPS-induced proIL-I/IL-I expression}

In order to investigate the mechanism of EORP boosting LPS-induced IL-I secretion by J774A. I cells, initially, we examined the effect of EORP pretreatment upon prolL-I protein production by J774A.I cells subjected to subsequent LPS stimulation. Prointerleukin-I (prolL-I, 34 kDa), an IL-I precursor is translated from IL-I mRNA and cleaved into a mature secreted form of IL-I (I7 kDa) by interleukin- Iconverting enzyme (ICE) (Cerretti et al., 1992). Pertaining to such a pathway, we first investigated prolL-I protein production within J774A.I cells using Western-blotting analysis. Resulting from time-course study, prolL-I production was detected in cell lysate between 3 and $9 \mathrm{~h}$ subsequent to LPS stimulation, the prolL-I protein level peaking at $6 \mathrm{~h}$, the prolL-I protein level in cell lysate gradually returning to the basal level at around $12 \mathrm{~h}$ subsequent to LPS stimulation (Fig. 5A). By contrast, for J774A. I cells pretreated with EORP, followed by LPS stimulation, the level of prolL-I protein expression was greater for such pretreated cells than was the case for unpretreated J774A.I cells (Fig. 5A). Following such investigation, we attempted to determine the necessary EORP incubation time for cultured J774A.I cells so as allowing them to develop the "hyper-induction" of prolL-I protein expression. In brief, during a $24 \mathrm{~h}$ period, at various specific times (i.e.

commencement, I, 3, 6, I2, I8, and 24 h subsequent to EORP pretreatment), such EORP pretreatment of J774A.I cells was halted by washing with PBS, followed by LPS challenge for an additional $6 \mathrm{~h}$. Following this, Western-blotting analysis of prolL-I production indicated that a minimum pretreatment of J774A.I cells with EORP for a period of around 3-6 h was required to induce "hyper-induction" of prolL-I protein expression (Fig. 5B). Furthermore, in order to investigate whether EORP modulates LPS-induced IL-I gene expression at the transcriptional level, the IL-I mRNA expression level was analyzed by RT-PCR method. Resulting from such experimentation, we found that LPS-induced IL-I mRNA expression for EORP-pretreated J774A.I cells were greater than was the case for un-pretreated counterpart cells (Fig. 5C).

\section{EORP pretreatment up-regulates LPS-induced prolL-I/IL-I expression via activation of mitogen-activated protein kinases (MAPKs)}

In order to further investigate the effect of EORP upon LPS-mediated signaling related to IL-I gene expression, we examined whether EORP pretreatment of J774A.I cells alters 
A

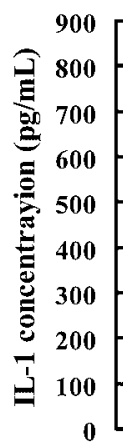

Pretreat.

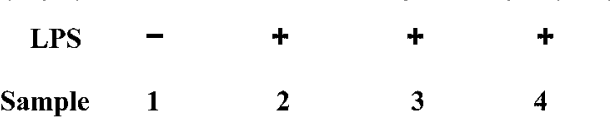

C
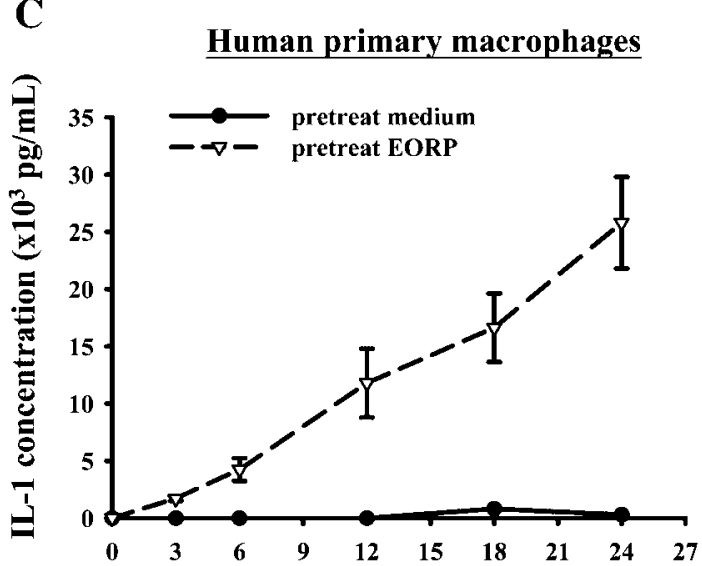

LPS treatment (h)

D

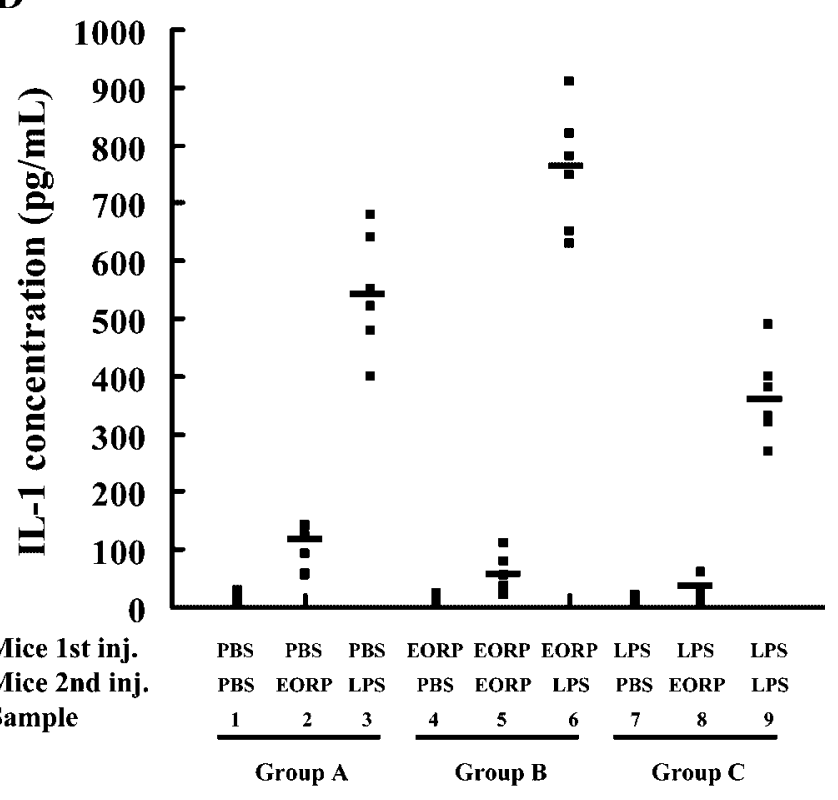

B

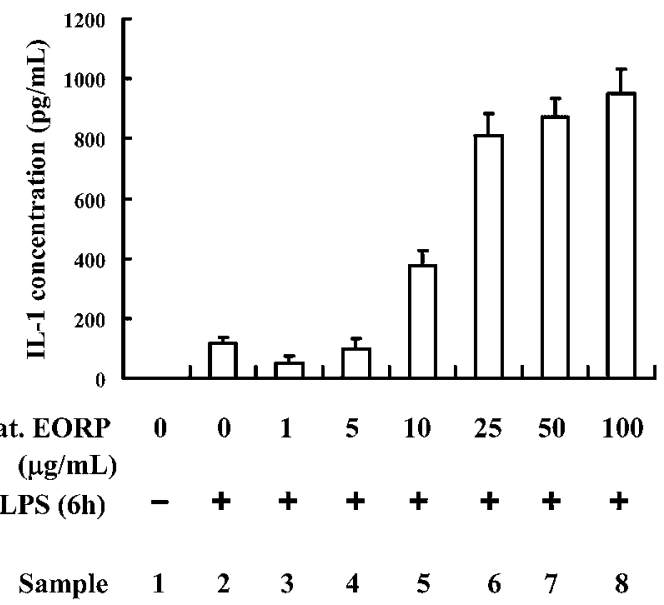

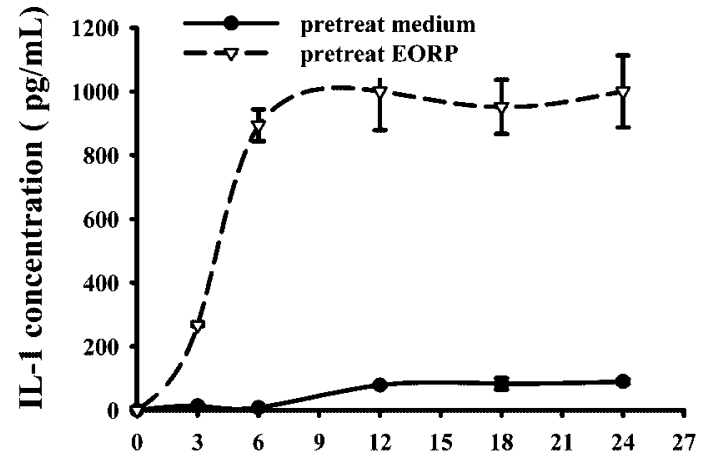

LPS treatment (h)

E

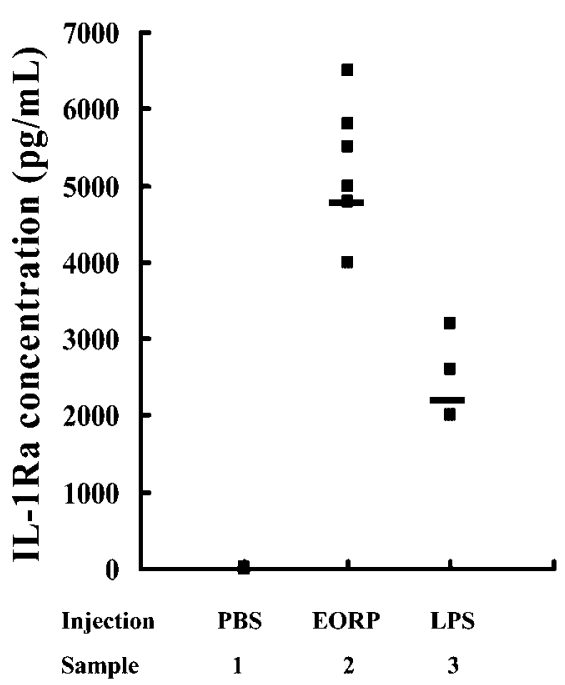

Fig. 4. 
A

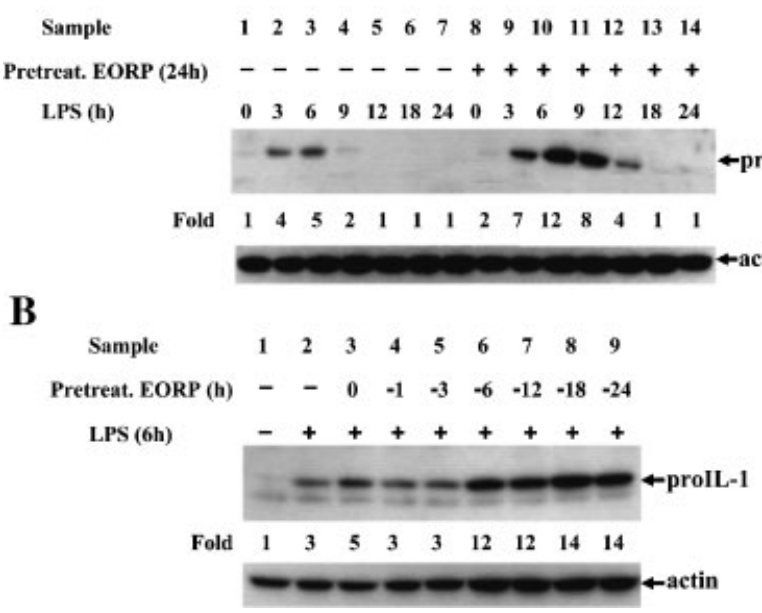

C Sample $\quad \begin{array}{llllllllllllllll}1 & 2 & 3 & 4 & 5 & 6 & 7 & 8 & 9 & 10 & 11 & 12 & 13 & 14 & 15 & 16\end{array}$ Pretreat. EORP (24h) LPS (h) $\begin{array}{llllllllllllllll}1 & 2 & 3 & 4 & 5 & 6 & 7 & 8 & 9 & 10 & 11 & 12 & 13 & 14 & 15 & 16 \\ - & - & - & - & - & - & - & - & + & + & + & + & + & + & +\end{array}$ $\begin{array}{llllllllllllllll}0 & 1 & 2 & 4 & 6 & 12 & 18 & 24 & 0 & 1 & 2 & 4 & 6 & 12 & 18 & 24\end{array}$ c..........- - - - - - - proIl-1 (563 bp) GAPDH (450 bp)

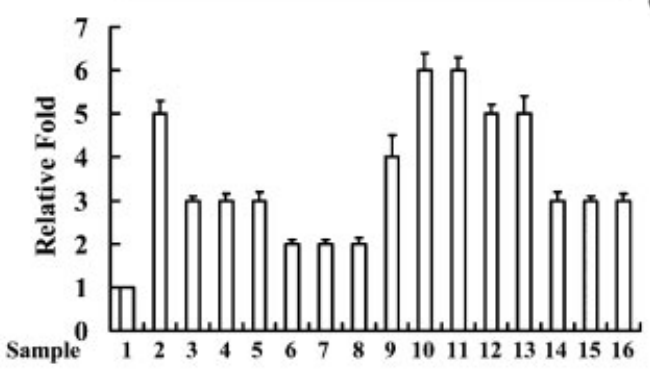

Fig. 5. Pretreatment of J774A.I cells to EORP increases LPS-induced IL-I gene expression. A: J774A.I cells were pretreated with EORP $(25 \mu \mathrm{g} / \mathrm{ml})$ or medium for $24 \mathrm{~h}$, and then challenged with LPS (I $\mu \mathrm{g} / \mathrm{ml})$ for the indicated time points. ProlL-I protein production was analyzed by Western blotting; $\mathbf{n}=3$. B: J774A. I cell were pretreated with EORP for the indicated time points prior to LPS stimulation for $6 \mathrm{~h}$. ProlL-I protein production was analyzed by Western blotting; $n=4$. C: J774A.I cells were pretreated with EORP (25 $\mu$ g/ml) or medium for $24 \mathrm{~h}$, and then stimulated with LPS (I $\mu \mathrm{g} / \mathrm{ml})$ for the indicated time points. IL-I and GAPDH $\mathrm{mRNA}$ expression level were analyzed by $\mathrm{RT}-\mathrm{PCR}$; $\mathrm{n}=3$.

the LPS-mediated downstream activation of MAPKs. Here, we demonstrated that LPS rapidly induced the activation of ERK, JNK, and p38 (Fig. 6A, samples I-7); whereas, by contrast, preexposure of J774A.I cells to EORP resulted in the rapid and substantial enhancement of the LPS-mediated activation of ERK, JNK, and p38 (Fig. 6A, samples 8-14). More specifically, in the first instance, the phosphorylation level of ERK reached a peak at around 20 min subsequent to LPS stimulation, and returned to the basal level at around $60 \mathrm{~min}$ subsequent to LPS stimulation. Further, the phosphorylation level of ERK was increased again at 240 and 360 min subsequent to LPS stimulation. Interestingly, for EORP-pretreated J774A.I cells, the phosphorylation level of ERK proved to be, I.5-, 3-, 6-, 5-, 2.5-, and I.5-fold greater than corresponding values for EORPfree cells at, respectively, 20, 40,60, 120, 240, and $360 \mathrm{~min}$ subsequent to LPS stimulation (Fig. 6A). The presence of phosphorylated JNK at a significant level above baseline was detected at around 20 min subsequent to LPS stimulation, whereas the level of LPS-induced JNK phosphorylation increased to only a slight extent for the EORP-pretreated J774A. I cells (Fig. 6A). The phosphorylation level of p38 quickly reached the maximal level at around 20 min subsequent to LPS stimulation, the level reducing significantly 40 min subsequent to LPS stimulation, although $\mathrm{p} 38$ phosphorylation again began to rise at around $240-360$ min subsequent to LPS stimulation. For EORP-pretreated J774A.I cells, the phosphorylation level of p38 following LPS stimulation was, one-, four-, two-, three-, and two-fold greater than the corresponding level for un-pretreated J774A. I cells at, respectively, 20, 40, 60, I20, and 240 min subsequent to LPS stimulation (Fig. 6A). In addition, we employed three pharmacological protein kinase (PK) inhibitors, to further assess the correlation between the EORP-enhanced activation of studied MAPKs and the corresponding cytokine expression. Following EORP pretreatment and prior to LPS treatment, J774A.I cells were incubated with one of PD98059, SP600I25- or SB203580, agents which specifically inhibit the activity of, respectively, MEKI, JNK, and p38. The doseresponse performance for the specific $\mathrm{PK}$ inhibitors tested was monitored by directly assaying individual PK activity (Hsu and Wen, 2002). As can be seen from Figure. 6B, application of the JNK inhibitor (SP600I25) and the p38 inhibitor (SB203580) significantly blocked EORP enhancement of LPS-induced prolLI protein expression. The application of PD98059 (a MEKI inhibitor), however, did not appear to diminish LPS-induced prolL-I protein expression for EORP-pretreated J774A.I cells (Fig. 6B), indicating that the pathway of MEKI $\rightarrow$ ERK plays a less-significant role than JNK and p38 related pathways as regards the induction of prolL-I. Furthermore, as measured by application of an MTT assay, no evidence of a cytotoxic effect was observed subsequent to J774A. I cells treatment with any of the PK inhibitors, at the specific concentrations at which these inhibitors were used (data not shown). Taken together, our current results indicate that EORP pretreatment of cultured J774A.I cells up-regulates LPS recognition and clearance by

Fig. 4. EORP pretreatment increases IL-I secretion from LPS-stimulated human primary macrophages, J774A. I cells and mice. A: J774A. I cells $\left(\mathrm{I} \times 10^{6} / \mathrm{ml}\right)$ were pretreated with EORP $(25 \mu \mathrm{g} / \mathrm{ml})$, EORP $(25 \mu \mathrm{g} / \mathrm{ml})$ plus LPS (I $\left.\mu \mathrm{g} / \mathrm{ml}\right)$ or medium (control) for $24 \mathrm{~h}$, and then challenged with LPS $(I \mu \mathrm{g} / \mathrm{ml})$ for $24 \mathrm{~h}$. IL-I concentration in culture supernatant was measured by ELISA. Data shown here expressed as the mean \pm SD, $n=3$. B: $J 774 A$. I cells $\left(I \times 10^{6} / \mathrm{ml}\right)$ were pretreated with the indicated concentration of EORP for $24 \mathrm{~h}$, and then challenged with LPS (I $\left.\mu \mathrm{g} / \mathrm{ml}\right)$ for $24 \mathrm{~h}$. IL-I concentration in culture supernatant was measured by ELISA. Data shown here expressed as the mean \pm SD, $n=4$. $C:$ Human blood monocytes-derived macrophages $\left(5 \times 10^{5} / \mathrm{ml}\right)$ and $\mathrm{J774A}$. I cells $\left(1 \times 10^{6} / \mathrm{ml}\right)$ were pretreated with EORP $(25 \mu \mathrm{g} / \mathrm{ml})$ or $\mathrm{medium}(\mathrm{control})$ for $24 \mathrm{~h}$, then challenged with LPS (I $\mu \mathrm{g} / \mathrm{ml})$ for the indicated time points. IL-I concentration in culture supernatant was measured by ELISA. Data shown here expressed as the mean $\pm S D, n=4$. D: C57BL/6J mice were initially injected intraperitoneally (i.p.) with one of the following, PBS $(200 \mu \mathrm{l})$, LPS $(5 \mathrm{mg} / \mathrm{kg})$ or EORP ( $100 \mathrm{mg} / \mathrm{kg})$. Twenty-four hours subsequent to such injection, mice were again i.p. injected with PBS (200 $\mu \mathrm{l})$, LPS $(10 \mathrm{mg} / \mathrm{kg})$ or EORP $(200 \mathrm{mg} / \mathrm{kg}) ; 1.5 \mathrm{~h}$ following which, the concentration of IL- I in the serum of the tested mice was measured by means of ELISA; $n=6$. E: C57BL/6j mice were initially injected i.p. with one of the following, PBS (200 $\mu \mathrm{l})$, LPS (I0 mg/kg), or EORP (200 mg/kg); $3 \mathrm{~h}$ following which, the concentration of IL- IRa in the serum of the tested mice was measured by means of ELISA; $n=6$. 
A

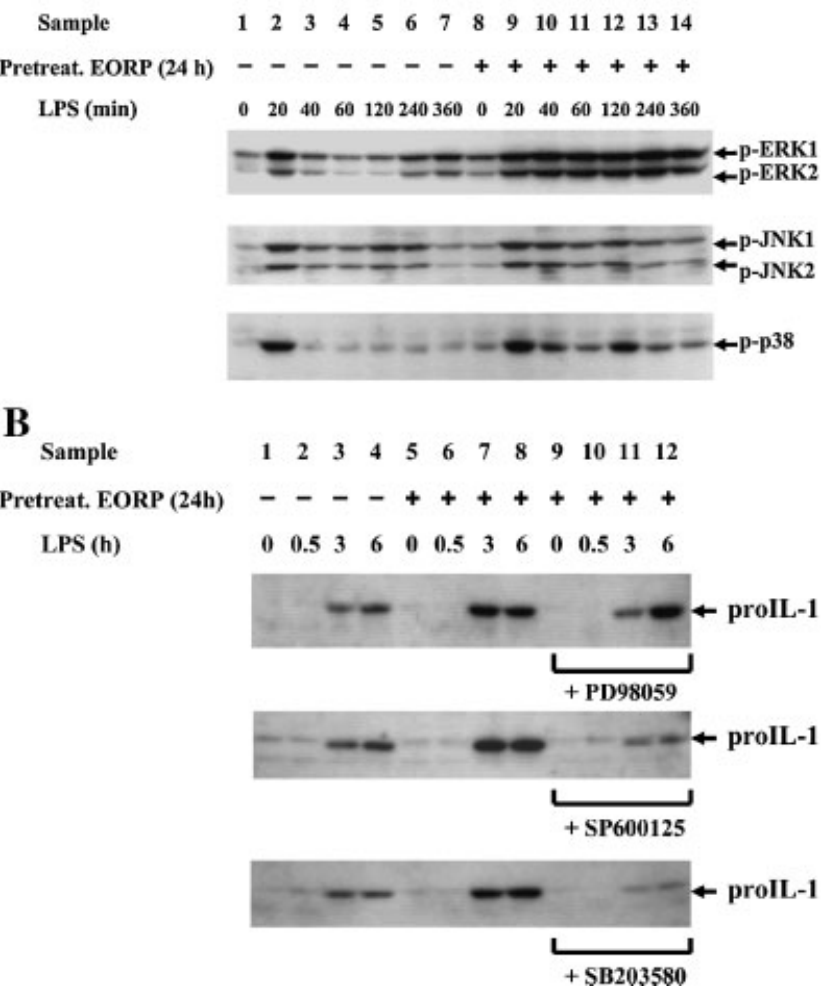

Fig. 6. EORP pretreatment up-regulates LPS-induced prolL-I/IL-I expression via activation of mitogen-activated protein kinases (MAPKs). A: EORP pretreatment up-regulates LPS-induced MAPKs phosphorylation. J774A.I cells were pretreated for $24 \mathrm{~h}$ with EORP (25 $\mu \mathrm{g} / \mathrm{ml})$ or medium and challenged with LPS $(1 \mu \mathrm{g} / \mathrm{ml})$ for the indicated time points. Phosphorylation level of ERK, JNK, and p38 were analyzed by Western blotting with anti-diphosphorylated ERK, anti-diphosphorylated JNK or anti-diphosphorylated p38 monoclonal antibody, respectively. One of three experiments is presented. B: J774A.I cells were pretreated for $24 \mathrm{~h}$ with EORP $(25 \mu \mathrm{g} / \mathrm{ml})$ or medium and stimulated with LPS $(\mathrm{I} \mu \mathrm{g} / \mathrm{ml})$ for the indicated time points in the present or absence of protein kinase inhibitors as indicated. ProlL-I protein expression level was analyzed by Western blotting. One of three experiments is presented.

J774A.I cells as well as the activation of certain MAPKs, leading to prolL-I/IL-I expression.

Effect of LPS uptake/internalization upon LPS-mediated activation and signaling related to IL-I gene expression

In the presence or absence, individually, of the endocytosis inhibitors cytochalasin D (Cooper, 1987) and colchicine (Isowa et al., 1999), cultured J774A. I cells were preincubated with EORP, we subsequently examining the effect of such endocytosis inhibitors upon EORP-induced LPS uptake/ internalization. As can be seen from confocal microscopy investigation (Fig. 7A), the presence of cytochalasin D (sample C-3) and also that of colchicine (sample C-4) significantly blocked the internalization of FITC-LPS compared with the analogous results for cytochalasin D/colchicine-free cells (Fig. 7A, samples C-2). Thus, in order to further investigate the presumed relationship between endocytosis-mediated LPS uptake/internalization and LPS-dependent activation of signaling related to IL-I gene expression within J774A.I cells. In essence, we analyzed both the LPS-induced downstream activation of test MAPKs and also IL-I gene expression by J774A.I cells in the presence, separately, of the endocytosis inhibitors, cytochalasin D and colchicine. Binding of LPS to J774A.I cells quickly induces phosphorylation of the MAPKs (ERK, JNK, and p38) (Fig. 7B, sample 2). Although endocytosis inhibitors such as cytochalasin $D$ and colchicine both exerted profound inhibitory effects upon LPS uptake/internalization (Fig. 7A, samples C-3 and C-4), their effects upon J774A.I cells activation and signaling would appear to be quite different. For example, both cytochalasin D and colchicine enhance p38 phosphorylation, and cytochalasin $\mathrm{D}$ up-regulates the phosphorylation level of ERKI/2, whereas colchicine acts to the contrary, it diminishing the phosphorylation level of ERKI/2 (Fig. 7B). When comparing such activity with LPS treatment of cultured J774A.I cells, cytochalasin D "super"-induces LPS-mediated prolL-I production, whereas, by contrast, colchicine exerts a significantly lower impact upon prolL-I induction. Further, at a relatively substantial concentration $(30 \mu \mathrm{M})$, colchicine actually inhibits prolL-I production (Fig. 7C). Moreover, using RT-PCR method, we further examined the effect of cytochalasin $D$ and colchicine upon IL-I mRNA expression. As can be seen from Figure 7D, there would not appear to be any significant difference in IL-I mRNA expression between the treatment of cultured J774A.I cells with cytochalasin D, colchicine or LPS, either with or without EORP pretreatment (Fig. 7D). At reasonably large doses, colchicine inhibited proll-I protein production but did not affect IL-I mRNA expression, suggesting that colchicine interferes with IL-I mRNA translation. Importantly, no cytotoxic effect of cytochalasin D and colchicine upon cultured J774A. I cells was observed as measured by an MTT assay (data not shown) during which assay, these cells were treated with various doses of cytochalasin $D$ or colchicine, the results indicating that colchicine inhibition of prolL-I production within J774A. I cells was unlikely to be due simply to cell damage.

\section{Discussion}

Herein we have demonstrated that an extract of $G$. lucidum polysaccharides (EORP) was able to be used to modulate the immune response of cultured J774A.I macrophage by enhancing CDI4-mediated endocytosis and by increasing TLR4-regulated IL-I gene expression (Fig. 8). In essence, we found that EORP increased the surface expression of both CDI4 and TLR4, and promoted LPS endocytosis, within such macrophages. Moreover, EORP pretreatment increased the level of LPS-induced IL-I secretion in mice (In Vivo) as well as within cultured human blood-derived primary macrophages, and murine macrophage J774A. I cells (in vitro). In addition, the serum concentration of IL-I Ra was dramatically increased for mice undergoing EORP injection, as compared to the basal level of IL-IRa release as revealed by analogous PBS injection. Of importance here, we have demonstrated that CDI4-mediated LPS endocytosis and TLR4-regulated IL-I gene expression within J774A.I cells are two separate and independent events. To the best of our knowledge, at time of writing, the precise mechanisms of EORP immuno-modulation of LPS-stimulated macrophages at a cellular level would appear to be somewhat unclear. The cellular uptake/clearance of certain bacteria and bacterial components (e.g., LPS) would appear to be predominantly performed by phagocytosis conducted by macrophages, this being one of the most-important features of the innate anti-bacterial immune response, and a feature which necessitates specific recognition of certain bacteria or bacterial components and endocytic pathways (Fearon and Locksley, 1996). The clearance of LPS by macrophages would appear to be a critical step for these cells' defence mechanism and one that reduces the relative toxicity of LPS, while still preserving 


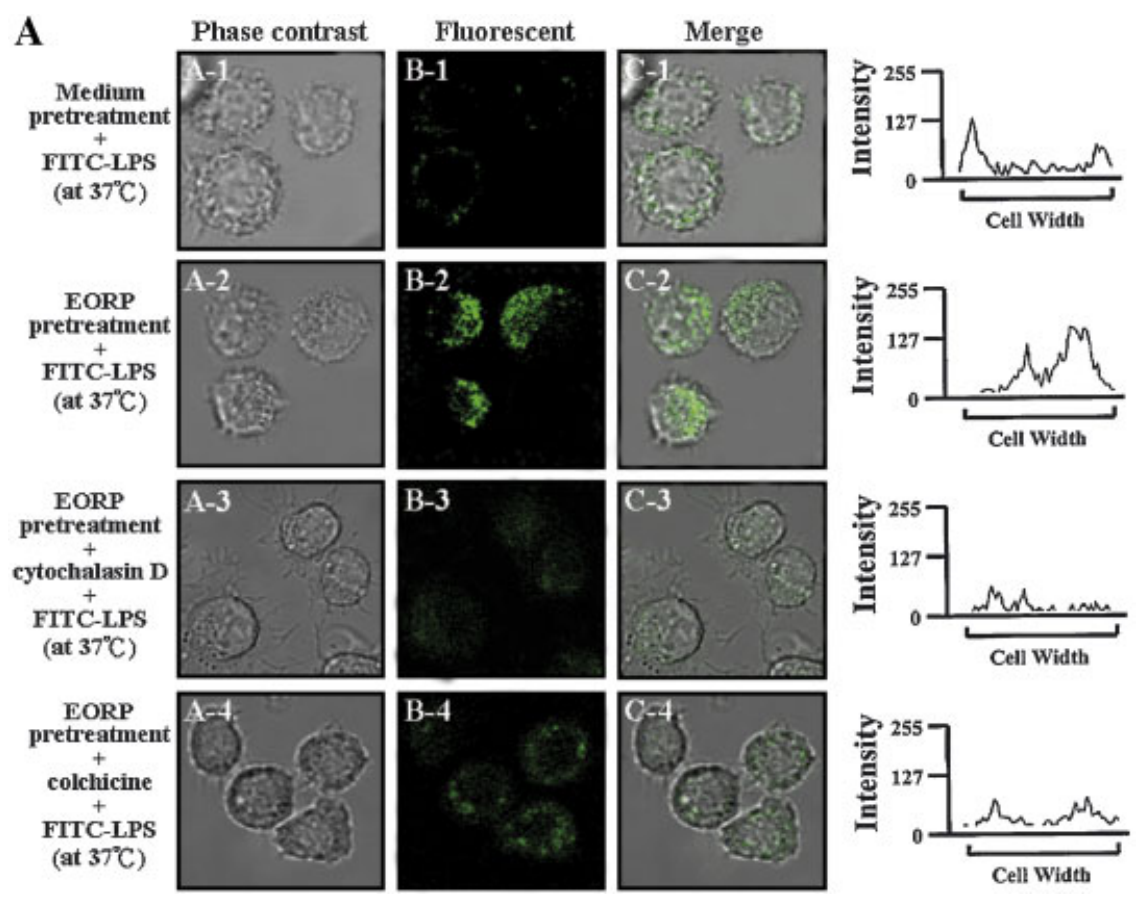

B

Sample
Cytochalasin D $(\mu \mathrm{M})$
Colchicine $(\mu \mathrm{M})$
LPS $(6 \mathrm{~h})$

$$
\begin{array}{cccccc}
1 & 2 & 3 & 4 & 5 & 6 \\
- & - & 1 & 10 & - & - \\
- & - & - & - & 10 & 30 \\
- & + & + & + & + & +
\end{array}
$$

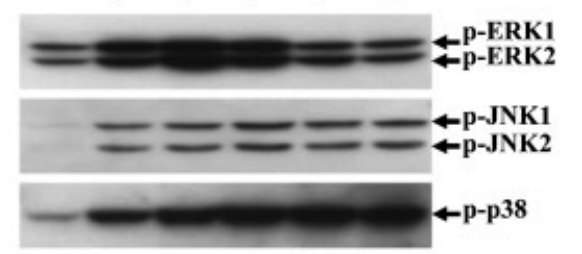

C

Sample

Cytochalasin D $(\mu \mathrm{M}) \quad-\quad-\quad 1 \quad 10 \quad-$

Colchicine $(\mu \mathrm{M}) \quad-\quad-\quad-\quad-1030$

LPS (6 h)

\section{D}

$\begin{array}{llllllllllll}\text { Sample } & 1 & 2 & 3 & 4 & 5 & 6 & 7 & 8 & 9 & 10 & 11 \\ \text { EORP pretreatment } & - & - & - & - & - & - & + & + & + & + & + \\ \text { Cytochalasin D }(\mu \mathrm{M}) & - & - & 1 & 10 & - & - & - & 1 & 10 & - & - \\ \text { Colchicine }(\mu \mathrm{M}) & - & - & - & - & 10 & 30 & - & - & - & 10 & 30 \\ \text { LPS }(1 \mathrm{~h}) & - & + & + & + & + & + & + & + & +\end{array}$

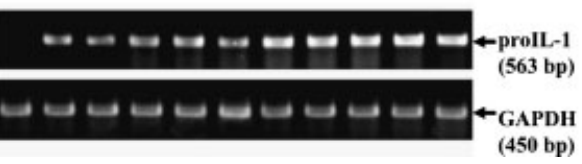

Fig. 7. Inhibitors of endocytosis reduce LPS internalization by J774A.I cells but not LPS dependent activation. A: Endocytosis inhibitors block LPS internalization by J774A.I cells. J774A.I cells were pretreated with EORP $(25 \mu \mathrm{g} / \mathrm{ml})$ for $24 \mathrm{~h}$, then washed with PBS, and treated with cytochalasin D $(10 \mu \mathrm{M})$, colchicines $(30 \mu \mathrm{M})$ or vehicle control (DMSO) for $30 \mathrm{~min}$, followed by FITC-LPS (green) treatment at $37^{\circ} \mathrm{C}$ for I h. After fixation, cells were examined under confocal microscope. Part A: phase contrast images; (part B) fluorescent images; (part C) merged images. B: Effect of endocytosis inhibitors on LPS-induced MAPKs phosphorylation in J774A.I cells. J774A.I cells were pretreated for 30 min with cytochalasin D $(I$ and $10 \mu \mathrm{M})$ or colchicine $(10$ and $30 \mu \mathrm{M})$ before being exposed to LPS $(I \mu \mathrm{g} / \mathrm{ml})$ for I $5 \mathrm{~min}$. Phosphorylation level of ERK, JNK, and p38 were analyzed by Western blotting with anti-diphosphorylated ERK, anti-diphosphorylated JNK, or anti-diphosphorylated p38 monoclonal antibody, respectively. One of three experiments is presented. C: Effect of endocytosis inhibitors on LPS-induced prolL-I production within J774A.I cells. J774A. I cells were pretreated with cytochalasin D (I and $10 \mu \mathrm{M})$ or colchicine $(10$ and $30 \mu \mathrm{M})$ for $30 \mathrm{~min}$, followed by LPS treatment for $6 \mathrm{~h}$, and then whole cell lysates were analyzed for prolL-I protein by Western blotting. One of three experiments is presented. D: Effect of endocytosis inhibitors on LPS-induced IL-I mRNA expression within J774A.I cells. J774A.I cells were pretreated for 30 min with cytochalasin $\mathrm{D}(\mathrm{I}$ and $\mathrm{I} 0 \mu \mathrm{M})$ or colchicine $(10$ and $30 \mu \mathrm{M})$ before being exposed to LPS $(\mathrm{I} \mu \mathrm{g} / \mathrm{ml})$ for I h. IL-I mRNA expression were analyzed by RT PCR. One of three experiments is presented. [Color figure can be viewed in the online issue, which is available at www.interscience.wiley.com.] 


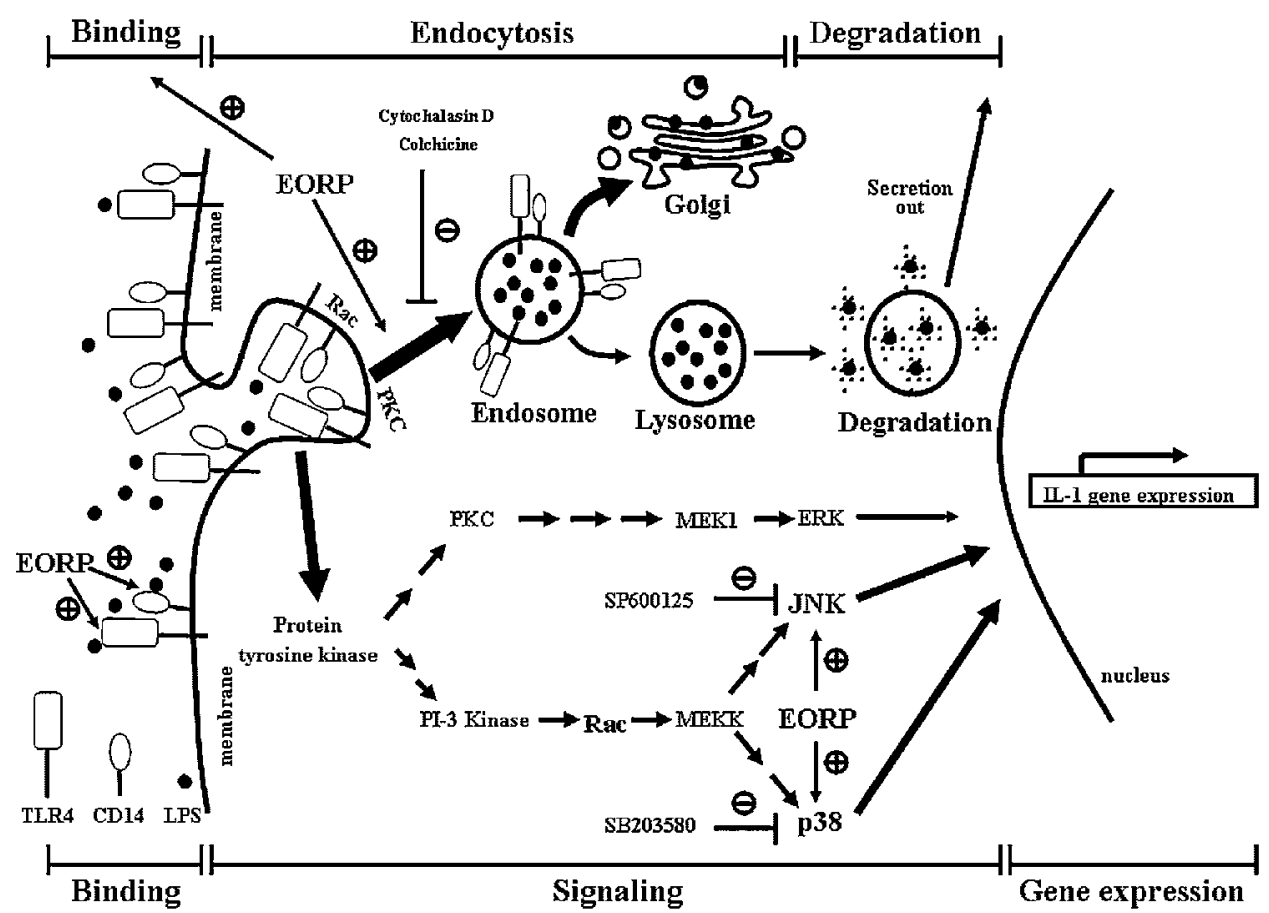

Fig. 8. The proposed mechanism of Ganoderma lucidum polysaccharides enhances the modulation of CDI4/TLR4-mediated endocytosis and signaling in IL-I cytokine expression.

some of these agents' potentially beneficial inflammationrelated immune response-triggering stimuli (Munford and Hall, 1986). LPS is able to be recognized by various macrophage-cell surface molecules such as TLR4, CDI4 (Wright et al., 1990), and/or MSR (Hampton et al., 199I). In our current study, we have demonstrated that LPS decreased TLR4 surface expression for cultured J774A. I macrophage cells, but increased the cell-surface expression of MSR, an outcome which could explain the reason for the observation herein that LPS pretreatment did increase LPS uptake by cultured macrophages, albeit only slightly; whereas, by contrast, EORP down-regulated the surface expression of MSR, but significantly up-regulated the surface expression of both TLR4 and CDI4. Moreover, it would appear that EORP (F3), but not the related fractions of $G$. lucidum polysaccharides, FI and F2, increased LPS binding to J774A.I cells and uptake by J774A. I cells. Using the TLR4 and CDI 4 blocking antibodies, which block TLR4 and CDI 4 binding to their ligands, we were able to demonstrate that CD I 4 is crucial for LPS binding to J774A. I cells and uptake by J774A. I cells, although surface expression of TLR4 does not correlate well with the level of such LPS binding to J774A. I cells. Such an outcome suggests that in the presence of LPS, TLR4 is only involved with LPS-mediated signaling but has nothing to do with LPS binding and uptake by J774A. I cells, a result which would appear to be entirely consistent with the results of certain other related studies (Dunzendorfer et al., 2004). Although CDI 4 plays an important role in the process of LPS binding and uptake by J774A.I cells, the presence of CDI4 blocking antibody in culture does not completely inhibit EORPenhanced LPS binding and uptake by J774A. I cells, suggesting that certain specific mechanism(s) are involved in this specific process.

In addition to J774A.I cells activation, membrane-bound CD I4 plays another important role within the spectre of endocytosis, a role that requires cytoskeleton rearrangements and polymerization (Latz et al., 2002; Dunzendorfer et al., 2004). In order to distinguish between the EORP-mediated increase of LPS uptake by J774A. I cells as occurring through a passive-entry process either across or through a CDI4-dependent classical form of endocytosis, we utilized certain drugs known to inhibit cytoskeleton polymerization such as cytochalasin $D$ and colchicine. From such investigation, we found that both cytochalasin D (Cooper, 1987) (blocking actin polymerization) and colchicine (lsowa et al., 1999) (blocking microtubule polymerization) significantly reduced the level of endocytosis of FITC-LPS, but elicited no interference with LPS-induced IL-I mRNA expression, indicating that the two processes, endocytosis and signal transduction, are normally independent. In addition, cytochalasin D was noted to increase the level of LPS-induced prolL-I production, as well as increasing the level of ERK, JNK, and p38 activation. We propose, thus, that the cytochalasin $\mathrm{D}$ disruption of actin polymerization prompts one certain type of stress for J774A.I cells, and is a process which intervenes in the propagation of mitogenic and/or activation signals (Zigmond, 1996). By contrast, colchicine selectively enhanced LPS-induced p38 activation, but diminished prolL-I production at a high concentration, suggesting that colchicine inhibits certain prolL-I/IL-I protein translation processes (Bocker et al., 200I).

The acquired hyper-responsiveness of IL-I gene expression via EORP is characterized by the increased ability of LPS to stimulate steady-state levels of IL-I mRNA, prolL-I protein, ILI secretion, and MAPK activation, but not the ICE activity level (data not shown) within cultured J774A. I cells. Further, such LPS stimulation also encompasses the enhancement of the serum level of IL-I secretion, in vivo, for mice that have been i.p. injected with LPS. The increasing level of EORP-mediated upregulation of IL-I secretion by J774A. I cells was observed to be more substantial than the corresponding level increase of the prolL-I protein. In our previous study, we found that EORP is 
acting through TLR4 (Hsu et al., 2004), accordingly, EORP pre-treatment induced tolerance towards LPS on LPS-induced TNF secretion (data not shown); however, EORP does not induce LPS tolerance on LPS-induced IL-I expression. We suggest that there are several active compounds in the extract of Reishi polysaccharides and that the enhancing effects we observed cannot be explained by our previous reports that EORP stimulates cells through TLR4. There would be some active compounds in EORP that specific enhance IL-I gene expression, yet some compounds would induce tolerance toward LPS on TNF secretion, and comprehension of the details of such a mechanism clearly warrant further investigation. In order to gain further insight into the mechanism of the EORP-mediated up-regulation of LPS-induced IL-I gene expression, we examined the protein expression of extracellular and intracellular signaling molecules involved in the TLR4-mediated signaling pathways. We, previously, have reported that LPS stimulates ERK, JNK, and P38 activation within J774A.I cells (Hsu and Wen, 2002); herein we have demonstrated that pre-exposure of such cells to EORP dramatically increases the LPS induction of ERK, JNK, and p38 activation. By contrast, however, LPS pretreatment if J774A. I macrophages appears to induce a state of cellular hyporesponsiveness to subsequent challenge with LPS, leading to a significant suppression of ERK, JNK, and p38 activation within certain macrophages, such an outcome being termed LPS tolerance (Dobrovolskaia et al., 2003; Karahashi and Amano, 2003; Leesun et al., 2004). Using inhibitors of the activation of certain MAPKs, we have demonstrated that SP600I 25 (JNK inhibitor) and SB203580 (p38 inhibitor), but not PD98059 (MEKI inhibitor), inhibit the EORP-mediated up-regulation of prolL-I protein production, indicating that EORP up-regulation of prolL-I protein results, principally, from the enhanced activation of JNK and p38. Moreover, we also found that EORP stimulation of cultured J774A.I macrophages led to a rapid degradation of IRAK-I protein in cytosol and the slight downregulation of the expression of IRAK-2 and IRAK-M (data not shown). Further, such EORP stimulation also led to the retention of a similar steady-state level of the protein MyD88 (data not shown). Since IRAK-M has been reported to be an important negative regulator of LPS-mediated signal transduction related to cytokines expression (Kobayashi et al., 2002), our results appear to suggest that the EORP-mediated enhancement of IL-I gene expression followed by LPS challenge is probably, at least partially, due to the associated reduction in IRAK-M expression by EORP treatment. IL-I released from activated macrophages has been reported to be one of the more-important reactions in the innate immune response of mice (Yamada et al., 2000).

It has been reported previously that the administration of IL-I protected mice from lethal $E$. coli infection as compared to untreated mice (Joshi et al., 2002). Herein, we have demonstrated that EORP pretreatment enhances LPS-induced IL-I secretion by macrophages for mice, as well as enhancing LPS-induced IL-I secretion by cultured human primary macrophages, and J774A.I cells in vitro, a scenario which may provide some form of protection effect for host species in response to pathogen challenge. Although EORP was observed to increase LPS-induced IL-I expression, interestingly, EORP also dramatically enhanced IL-I Ra secretion by C57BL/6] mice within $3 \mathrm{~h}$ of LPS i.p. injection. Since IL-IRa is a member of the IL-I superfamily, the actions of which include the competitive inhibition of the binding of IL-I to an IL-I receptor (IL-IR) (Hannum et al., 1990), the current "parallel” EORP regulation of IL-I and IL-IRa could, in fact, be part of a mechanism designed to preserve the level of access of IL-I to IL-IR (Arend et al., I 998). The increase in the serum level of IL-IRa for EORP-treated mice and cultured macrophages would appear to reduce the availability of the IL-I to IL-I receptor; therefore, the net reaction may be to shift the biological functions of IL-I back toward baseline.

It has been reported previously that intraperitoneal injection of LPS is more lethal for IL-IRa knockout mice than for normal mice (Hirsch et al., 1996). Moreover, compared to normal mice or IL-I Ra transgenic mice, mice lacking endogenous IL-I Ra have been shown to be less susceptible to infection with Listeria monocytogenes than is the case of control mice, such an observation supporting the notion of the relative importance of IL-I as regards imparting resistance to infection with intracellular organisms for mice. Conversely, IL-IRa overproducers are protected from the lethal effects of LPS but appear to be more susceptible to listeriosis than is the case of control mice. Serum levels of IL-I following an LPS challenge are reduced for IL-IRa nulls and increased for IL-IRa overproducers when compared to corresponding levels for control individuals (Hirsch et al., 1996). Our current results which suggest that the concentration of IL- IRa in serum and conditioned medium deriving from, respectively, EORP-stimulated mice and macrophages, was substantially larger than corresponding levels for controls, such an outcome likely leading to an increase of serum and supernatant of cultured cells in the level of soluble IL-I (non-receptor bound IL-I) during LPS stimulation. The balance between endogenous IL-I and IL-I Ra is, thus, important in influencing the host response to micro-organisms infection or abnormal inflammation (Hirsch et al., 1996). Hence, the outcomes of certain IL-I-mediated processes may be dependent upon the relative inherent endogenous quantities of IL-I and IL-IRa, rather than upon the absolute quantity of IL-I in serum of mice or supernatant of cultured cells alone. In summary, we have demonstrated that EORP increases surface expression of CDI4 and TLR4, respectively, and enhances CDI4-dependent binding and endocytosis of LPS for cultured murine macrophage cells. On the other hand, EORP promotes the TLR4-mediated hyper-responsiveness of IL-I gene expression and the activation of MAPKs for cultured macrophages subsequent to LPS challenge. In addition, EORP challenge dramatically increases IL-I Ra expression by mice. The results of endocytosis-inhibitor blockade of LPS internalization in the absence of any apparent interference with LPSdependent activation for J774A.I macrophages indicate that these two outcomes are independent. In the first instance, our current results have provided an understanding of mechanisms of the EORP-mediated up-regulation of IL-I gene expression and the enhancement of LPS endocytosis, an insight, which is relevant to EORP as regards the modulation of the normal antibacterial immune response and the clearance of bacteria or related components from the host.

\section{Acknowledgments}

This work was supported by National Science Council, Taiwan (NSC 94-2I20-M-010-002 and NSC 93-23 I4-B-010-003 to $\mathrm{H}-\mathrm{Y} \mathrm{Hsu})$, National Health Research Institutes, Taiwan (NHRI-EX93-92 I ISI to H-Y Hsu); the Ministry of Education, Taiwan, on Program for Promoting Academic Excellence of Universities (A-9I-B-FA09-2-4 to H-Y Hsu); a grant from Ministry of Education, Aim for the Top University Plan (95A-CDOI-PPG-IO to H-Y Hsu); Academia Sinica (Thematic project to $\mathrm{H}-\mathrm{Y}$ Hsu, S-T Chen and W-B Yang) and Academia Sinica, Taiwan (C-H Wong).

\section{Literature Cited}

Arend WP, Malyak M, Guthridge CJ, Gabay C. 1998. Interleukin-I receptor antagonist: Role in Biology. Annu Rev Immunol 16:27-55.

Bocker U, Sirenko OI, Morris JS, Sartor RB, Singer MV, Haskill JS, Watson JM. 200 I. Expression and localization of IL-I beta mRNA is interrelated with cytoskeletal rearrangement in monocytes stimulated by adherence: $A$ light microscopy in situ hybridization study. Immunol Cell Biol 79:444-453.

Cerretti DP, Kozlosky C], Mosley B, Nelson N, Van Ness K, Greenstreet TA, March C. Kronheim SR, Druck T, Canniz LA. 1992. Molecular cloning of the interleukin-I beta converting enzyme. Science 256:97-100 
Chen HS, Tsai YF, Lin S, Lin CC, Khoo KH, Lin CH, Wong CH. 2004. Studies on the immunomodulating and anti-tumor activities of Ganoderma lucidum (Reishi) polysaccharides. Bioorg Med Chem 12:5595-560।.

Chien CM, Cheng JL, Chang WT, Tien MH, Tsao CM, Chang YH, Chang HY, Hsieh JF, Wong $\mathrm{CH}$, Chen ST. 2004. Polysaccharides of Ganoderma lucidum alter cell immunophenotypic expression and enhance CD56+ NK-cell cytotoxicity in cord blood. Bioorg Med Chem 12:5603-5609

Cooper JA. 1987. Effects of cytochalasin and phalloidin on actin. J Cell Biol 105:1473-1478.

Cowan DB, Noria S, Stamm CL, Garcia M, Poutias DN, del Nido PJ, McGowan FXJr. 2001. Lipopolysaccharide internalization activates endotoxin-dependent signal transduction in cardiomyocytes. Circ Res 88:49|-498.

cardiomyocytes. Circ Res 88:49|-498.
Dinarello CA. I 996. Biologic basis for interleukin-I in disease. Blood 87:2095-2/47.

Dobrovolskaia MA, Medvedev AE, Thomas KE, Cuesta N, Toshchakov V, Ren T, Cody MJ, Michalek SM, Rice NR, Vogel SN. 2003. Induction of in vitro reprogramming by toll-like receptor (TLR) 2 and TLR4 agonists in murine macrophages: effects of tlr "homotolerance" versus "heterotolerance" on nf- B signaling pathway components. Immunol 170:508-519.

Dunzendorfer S, Lee HK, Soldau K, Tobias PS. 2004. TLR4 is the signaling but not the lipopolysaccharide uptake receptor. J Immunol 173:1166-1170.

Fearon DT, Locksley RM. 1996. The instructive role of innate immunity in the acquired immune response. Science 272:50-53.

Gordon S. 2002. Pattern recognition receptors: Doubling up for the innate immune response. Cell II I:927-930.

Goyert SM, Ferrero E, Rettig WJ, Yenamandra AK, Obata F, Le Beau MM. 1988. The CDI4 monocyte differentiation antigen maps to a region encoding growth factors and receptors. Science 239:497-500.

Hampton RY, Golenbock DT, Penman M, Krieger M, Raetz CR. 1991. Recognition and plasma clearance of endotoxin by scavenger receptors. Nature 352:342-344.

Hannum CH, Wilcox CJ, Arend WP, Joslin FG, Dripps DJ, Heimdal PL, Armes LG, Sommer A Eisenberg SP, Thompson RC. 1990. Interleukin-I receptor antagonist activity of a human interleukin-I inhibitor. Nature 343:336-340.

Hirsch E, Irikura VM, Paul SM, Hirsh D. 1996. Functions of interleukin I receptor antagonist in gene knockout and overproducing mice. Proc Natl Acad Sci USA 93:1 1008-11013.

Hornef MW, Frisan T, Vandewalle A, Normark S, Richter-Dahlfors A. 2002. Toll-like receptor 4 resides in the Golgi apparatus and colocalizes with internalized lipopolysaccharide in intestinal epithelial cells. J Exp Med 195:559-570.

Hsu HY, Hua KF, Lin CC, Lin CH, Hsu J, Wong CH. 2004. Extract of reishi polysaccharides induces cytokine expression via toll-like receptor 4-modulated protein kinase signaling pathways. J Immunol 173:5989-5999.

Hsu HY, Chiu SL, Wen MH, Chen KY, Hua KF. 200I. Ligands of macrophage scavenger receptor induce cytokine expression via differential modulation of protein kinase signaling pars. Biol Com 276.28719-28730.

Hsu MJ, Lee SS, Lee ST, Lin WW. 2003. Signaling mechanisms of enhanced neutrophil phagocytosis and chemotaxis by the polysaccharide purified from Ganoderma lucidum. $\mathrm{Br}$ Pharmacol 139:289-298

Hsu HY, Wen MW. 2002. Lipopolysaccharide-mediated reactive oxygen species and signal transduction in the regulation of interleukin-I gene expression. J Biol Chem 277:22।3122139

Isowa N, Xavier AM, Dziak E, Opas M, McRitchie DI, Slutsky AS, Keshavjee SH, Lui M. 1999. LPS-induced depolymerization of cytoskeleton and its role in TNFa production by rat pneumocytes. Am J Physiol 277:L606-615.

Iwasaki A, Medzhitov R. 2004. Toll-like receptor control of the adaptive immune responses. Nat Immunol 5:987-995.

Joshi VD, Kalvakolanu DV, Hebel JR, Hasday JD, Cross AS. 2002. Role of caspase I in murine antibacterial host defenses and lethal endotoxemia. Infect Immun 70:6896-6903.

Karahashi H, Amano F. 2003. Endotoxin-tolerance to the cytotoxicity toward a macrophagelike cell line, J774. I, induced by lipopolysaccharide and cycloheximide: Role of p38 MAPK in induction of the cytotoxicity. Biol Pharm Bull 26:1249-1259.
Kay J, Calabrese L. 2004. The role of interleukin-I in the pathogenesis of rheumatoid arthritis. Rheumatology 43:iii2-iii9.

Kitchens RL, Munford RS. 1998. CDI4-dependent internalization of bacterial lipopolysaccharide (LPS) is strongly influenced by LPS aggregation but not by cellular responses to LPS. J Immunol 160:1920-1928.

Kobayashi K, Hernandez LD, Galan JEJr, Janeway CA, Medzhitov R, Flavell RA. 2002. IRAK-M is a negative regulator of toll-like receptor signaling. Cell II0:191-202.

Kriegsmann J, Gay S, Brauer R. 1993. Endocytosis of lipopolysaccharide in mouse macrophages. Cell Mol Biol 39:791-800.

Latz E, Visintin A, Lien E, Fitzgerald KA, Monks BG, Kurt-Jones EA, Golenbock DT, Espevik T. 2002. Lipopolysaccharide rapidly traffics to and from the Golgi apparatus with the Toll-like receptor 4-MD-2-CDI4 complex in a process that is distinct from the initiation of signal transduction. J Biol Chem 277:47834-47843.

Leesun K, Butcher BA, Denkers EY. 2004. Toxoplasma gondii interferes with lipopolysaccharide-induced mitogen-activated protein kinase activation by mechanisms distinct from endotoxin tolerance. J Immunol 172:3003-3010.

Lin KI, Kao YY, Kuo HK, Yang WB, Chou A, Lin HH, Yu AL, Wong CH. 2006. Reishi polysaccharides induce immunoglobulin production through the TLR4/TLR2-mediated induction of transcription factor Blimp-I. J Biol Chem 28I:24III-24I23.

Lipsky NG, Pagano RE. 1985. A vital stain for the Golgi apparatus. Science 228:745747.

Loppnow H, Werdan K, Reuter G, Flad HD. 1998. The interleukin-I and interleukin-I converting enzyme families in the cardiovascular system. Eur Cytokine Network 9:675 680 .

Munford RS, Hall CL. 1986. Detoxification of bacterial lipopolysaccharides (endotoxins) by a human neutrophil enzyme. Science 234:203-205.

Nomura F, Akashi S, Sakao Y, Sato S, Kawai T, Matsumoto M, Nakanishi K, Kimoto M, Miyake $\mathrm{K}$, Takeda K, Akira S. 2000. Cutting edge: endotoxin tolerance in mouse peritoneal macrophages correlates with down-regulation of surface toll-like receptor 4 expression. J Immunol 164:3476-3479.

Poltorak A, He X, Smirnova I, Liu MY, Van Huffel C, Du X, Birdwell D, Alejos E, Silva M, Galanos C, Freudenberg M, Ricciardi-Castagnoli P, Layton B, Beutler B. 1998. Defective LPS signaling in $\mathrm{C} 3 \mathrm{H} / \mathrm{HeJ}$ and $\mathrm{C} 57 \mathrm{BL} / \mathrm{IOScCr}$ mice: Mutations in Tlr4 gene. Science 282 2085-2088.

Poussin C, Foti M, Carpentier JL, Pugin J. 1998. CDI4-dependent endotoxin internalization via a macropinocytic pathway. J Biol Chem 273:20285-20291.

Raetz CR, Whitfield C. 2002. Lipopolysaccharide endotoxins. Annu Rev Biochem 71:635700 .

Stuart LM, Ezekowitz RA. 2005. Phagocytosis: Elegant complexity. Immunity 22:539-550.

Thieblemont N, Wright SD. 1997. Mice genetically hyporesponsive to lipopolysaccharide (LPS) exhibit a defect in endocytic uptake of LPS and ceramide. J Exp Med 185:20952100.

Via LE, Fratti RA, McFalone M, Pagan-Ramos E, Deretic D, Deretic V. 1998. Effects of cytokines on mycobacterial phagosome maturation. J Cell Sci I I I:897-905.

Waage A, Espevik T. 1988. Interleukin I potentiates the lethal effect of tumor necrosis facto alpha/cachectin in mice. J Exp Med 167:1987-1992.

Wang YY, Khoo KH, Chen ST, Lin CC, Wong CH, Lin CH. 2002. Studies on the immunomodulating and antitumor activities of Ganoderma lucidum (Reishi) polysaccharides: Functional and proteomic analyses of a fucose-containing glycoprotein fraction responsible for the activities. Bioorg Med Chem 10:1057-1062.

Wright SD, Ramos RA, Tobias PS, Ulevitch RJ, Mathison JC. 1990. CDI4, a receptor for complexes of lipopolysaccharide (LPS) and LPS binding protein. Science. 249:1431-1433.

Yamada H, Mizumo S, Horai R, Iwakura Y, Sugawara I. 2000. Protective role of interleukinin mycobacterial infection in IL-I alpha/beta double-knockout mice. Lab Investig 80:759-767.

Zigmond SH. 1996. Signal transduction and actin filament organization. Curr Opin Cell Biol $8: 66-73$. 